\title{
Analysis of observations backing up the existence of VLF and ionospheric TEC anomalies before the Mw6.1 earthquake in Greece, January 26, 2014
}

\author{
F. Sanchez-Dulcet ${ }^{\mathrm{a}, *}$, M. Rodríguez-Bouza ${ }^{\mathrm{a}}$, H.G. Silva ${ }^{\mathrm{b}, \mathrm{c}}$, M. Herraiz $^{\mathrm{a}, \mathrm{d}}$, M. Bezzeghoud ${ }^{\mathrm{b}}$, P.F. Biagi ${ }^{\mathrm{e}}$

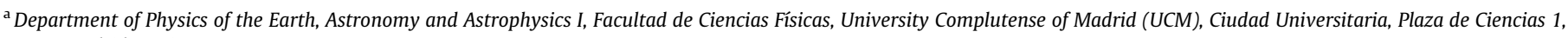 \\ 28040 Madrid, Spain \\ ${ }^{\mathrm{b}}$ Departamento de Física, ECT, Instituto de Ciências da Terra, Universidade de Évora, Rua Romão Ramalho 59, 7002-554 Évora, Portugal \\ ${ }^{\mathrm{c}}$ Atmospheric Chemistry Research Group, University of Bristol, Cantock's Close, Bristol BS8 1TS, UK \\ dinstitute of Geosciences (UCM, CSIC), Ciudad Universitaria, Calle José Antonio Novais 12, 28040 Madrid, Spain \\ e Department of Physics, University of Bari, Campus Universitario “Ernesto Quagliariello", Vía G. Amendola 173, 70126 Bari, Italy
}

\section{A R T I C L E I N F O}

\section{Article history:}

Received 10 October 2014

Received in revised form 17 June 2015

Accepted 5 July 2015

Available online $\mathrm{xxxx}$

\section{Keywords:}

Lithosphere-atmosphere-ionosphere coupling

Earthquake precursors

Very-low-frequency radio transmissions

TEC anomaly

\begin{abstract}
A B S T R A C T
The present work integrates ground-based ionosphere measurements using very-low-frequency radio transmissions with satellite measurements of the total electron content to draw common conclusions about the possible impact that the Mw6.1 earthquake that took place in Greece on January 26, 2014, had on the ionosphere.

Very-low-frequency radio signals reveal the existence of an $\sim 4$-day anomaly in the wavelet spectra of the signals received inside the earthquake preparation zone and a significant increase in the normalized variance of the signals prior to the earthquake (approximately 1 day before).

Through total electron content analysis, it was possible to identify a clear anomaly from 15:00 until 20:00 UT on the day before the earthquake that appears again on the day of the earthquake between 07:00 UT and 08:00 UT. The anomalous values reach TEC *Sigma 4.36 and 3.11, respectively. Their spatial and temporal distributions give grounds to assume a possible link with the earthquake preparation. The geomagnetic, solar and weather conditions during the considered period are presented and taken into account.

This work is an initial and original step towards a multi-parameter approach to the problem of the possible earthquake-related effects on the ionosphere joining observations made from both ground stations and satellites. A well-founded knowledge of these phenomena is clearly necessary before dealing with their application to earthquake prediction purposes.
\end{abstract}

(c) 2015 Elsevier Ltd. All rights reserved.

\section{Introduction}

The study of lithosphere-atmosphere-ionosphere coupling (LAI) is mainly focused on the analysis and comprehension of atmospheric and ionospheric anomalies caused by extreme lithospheric events (Molchanov et al., 2004; Pulinets and Ouzounov, 2011). Earthquakes are considered to be sources of atmosphereionosphere anomalies mainly because of the surface ionization resulting from the radioactive decay of radon emanations (Silva

\footnotetext{
* Corresponding author at: Facultad de Ciencias Físicas, Ciudad Universitaria, Plaza de Ciencias 1, 28040 Madrid, Spain.

E-mail addresses: fjsanche@ucm.es (F. Sanchez-Dulcet),mrodriguezbouza@ucm. es (M. Rodríguez-Bouza), hgsilva@uevora.pt (H.G. Silva), mherraiz@ucm.es (M. Herraiz), mourad@uevora.pt (M. Bezzeghoud), pierfrancesco.biagi@uniba.it (P.F. Biagi).
}

et al., 2013) and the generation of geo-electric charges (Freund, 2013). Such phenomena propagate through the atmosphere causing thermal anomalies (Kakinami et al., 2013) and atmospheric electric field perturbations (Silva et al., 2011). Ultimately, they affect the ionosphere causing very-low-frequency and lowfrequency (VLF/LF) radio transmission disturbances (Righetti et al., 2012), extremely low-frequency and very-low-frequency (ELF/VLF) magnetic-field radiation (Nemec et al., 2008) and total electron content (TEC) anomalies (Yao et al., 2012), among other phenomena. A consistent model that was recently developed (Harrison et al., 2014) considers the global atmospheric electric circuit to be the coupling agent between the surface ionization and the ionosphere perturbation, validating LAI observations. Actually, the first observation of a possible effect of earthquakes on the ionosphere was obtained on the occasion of the Alaska, March 1964, earthquake. The comparison of seismograms of this 9.2 magnitude 
event with ionograms recorded in observatories close to the epicentre revealed the presence of anomalous vertical displacements of the ionosphere before and after the earthquake (Moore, 1964; Davies and Baker, 1965). From this point on, the research into possible earthquake-ionosphere relationships bloomed and was initially aimed at the behaviour of different layer characteristics, such as height, density, and composition. (see Kazimirovsky et al., 2003; Pulinets and Boyarchuk, 2004, for further references).

On the one hand, radio transmissions have been widely used in atmospheric electricity studies to detect thunderstorms and sprites. Such studies considered radio signals from networks developed for navigation, such as OMEGA and LORAN, until their elimination in 1997 and 2010, respectively. Similarly, these radio transmissions were used to search for ionospheric precursors possibly related with significant magnitude earthquakes since the pioneering work of Gokhberg et al. (1989). More recently, signals of $15-50 \mathrm{kHz}$ from powerful VLF/LF transmitters for navigational and time services have been deployed in Europe, Asia, USA and Australia and are being used to study possible ionosphere perturbations related to earthquakes. Much work has been done on this subject in Europe both for LF (Biagi et al., 2006) and VLF signals (Biagi et al., 2008; Rozhnoi et al., 2009), but Japan and the Far Eastern regions, i.e., areas with very high seismic activity, are where the subject has received the most attention. Important results have been achieved in recent years. Saha et al. (2014) proved that the fluctuation ratio of the impulsivity of LF signals shows a significant correlation with the closeness parameter defined as the ratio between the earthquake preparation radius, $R$, (Dobrovolsky et al., 1979) and the distance of the earthquake epicentre to the radio transmitter, $D$. This result is consistent with the work of Silva et al. (2013) who found a correlation between radon anomalies and the parameter $S$ defined by the ratio $S=R / D-1$

On the other hand, the directions of the studies related to possible earthquake-induced ionospheric perturbations changed dramatically in the early years of this century, when the Total Electron Content, TEC, data obtained from Global Navigation Satellite System (GNSS) signal delays were considered. These data allow for the detection of changes in the electronic density of the ionosphere worldwide in a very accurate and quick way and can be applied to both earthquakes and tsunamis (Artru et al., 2005; Liu et al., 2012).

The present work integrates ground-based measurements (VLF) and satellite derived data (TEC) to draw common conclusions about the possible impact that the Mw6.1 earthquake in Greece (January 26, 2014) had on the ionosphere. This is a first step towards a multi-parameter approach to earthquake precursors as discussed in the literature (Ouzounov et al., 2011).

\section{Seismic characterization}

In the Mediterranean region, the seismic activity is due to the northward convergence, with velocities ranging between 4 and $10 \mathrm{~mm} / \mathrm{yr}$, of the African plate with respect to the Eurasian plate along a complex plate boundary. This region is marked by a pre-instrumental seismicity (pre-20th century) and several strong earthquakes recorded during the last centuries. Earthquakes have historically caused extensive damage across central and southern Greece (e.g., the 1903 M8.2 Kythera earthquake), along the North Anatolian Fault Zone (e.g., the 1939 M7.8 Erzincan and 1999 M7.6 Izmit earthquakes), Cyprus, Sicily (e.g., the 1693 M8.0 Sicily earthquake; the M7.2 December 28, 1908 Messina earthquake), Crete, the Nile Delta, Northern Libya, the Atlas Mountains of North Africa (e.g., the 1980 M7.3 El Asnam earthquake) and the Iberian Peninsula (the Lisbon earthquake of November 1, 1755, M8.5).

\subsection{Greece seismicity}

Focusing on Greece, Fig. 1 shows the earthquakes for the period 1980-2014 (USGS data base) with magnitudes greater than 4.0. From this figure we can deduce that the seismicity of this area is very high, especially along the Hellenic subduction zone of southern Greece where the plate velocity reaches $35-40 \mathrm{~mm} / \mathrm{yr}$ and generates the highest rates of seismicity of the Mediterranean region. This seismicity is a manifestation of crustal normal faulting and extensional tectonics associated with back-arc spreading. Greece is the most seismic country in Europe, and Cephalonia, Western Greece, is particularly liable to experience earthquakes because it is located just to the east of a major tectonic fault line where the European and Aegean plates meet at a slip boundary.

\subsection{The 26th January earthquake}

On 26th January 2014 at 13:55 UTC (15:55 local time), an earthquake (Mw6.1) occurred at Argostólion, Cephalonia, $\left(38.23^{\circ} \mathrm{N}\right.$, $20.48^{\circ} \mathrm{E}$ ). It had a focal mechanism dominated by a strike-slip (Fig. 1) compatible with the fault that possibly generated the event, the Cephalonia Transform Fault that is a dextral strike-slip fault with a thrust component. A black star on Fig. 2 represents the earthquake epicentre. Eight days later, on 3rd February, a second M6.0 earthquake hit this region at 03:08 UTC (05:08 local time). This earthquake sequence led to important damages in the area and numerous aftershocks were recorded following the main shock. In the first 9 days, 434 M3+ earthquakes, 51 M4+ earthquakes, and 3 M5+ earthquakes struck the zone. The two M6 earthquakes took place on the same island as the 3 destructive events that occurred between August 9th and 12th of 1953 (Fig. 2). Those earthquakes had magnitudes of $6.4,6.8$ and 7.2 and resulted in hundreds of casualties and significant damage all over the island and also in Zante and Ithaca. In the following months, $80 \%$ of the population left the island.

\subsection{Temporal evolution of the local seismicity}

The upper panel of Fig. 3 shows the temporal distribution of the local seismic activity over approximately 10 years (Mw $>2.0$, EMSC database). Clustering cases are clearly observed when magnitudes are plotted for the period from 2004-10-10 to 2014-06-30. In this figure, there are 4 seismic clusters (marked with vertical lines) that can be very well identified by intense seismic activity triggered by an earthquake larger than Mw5.5. These events are represented with large circles; the main shock (MS) of 26th January 2014 (Mw6.1) is marked with a star. The time succession shows that most of the largest events could be related to their aftershock area. In fact, we observe a typical aftershock distribution, with an activity that decreases in time after each main shock. A lack of seismic activity with Mw $>4.0$ nearly 100 days before the MS can be seen in the lower panel of Fig. 3. The zoom around the MS time period clearly shows a moderate foreshock, $\mathrm{F}$ (marked by a diamond) of Mw4.8, on 11th January 2014, 15 days before MS, and a large aftershock, A (marked by a large circle) of Mw6.0, on 6th February 2014. The seismic swarm triggered by the MS is the most significant feature of the represented seismic catalogue for this region.

\section{Physical conditions}

There are different physical phenomena that are able to affect the ionospheric conditions producing small perturbations that can be misinterpreted as earthquake-related disturbances. We pay attention to the three that are considered the most important. 


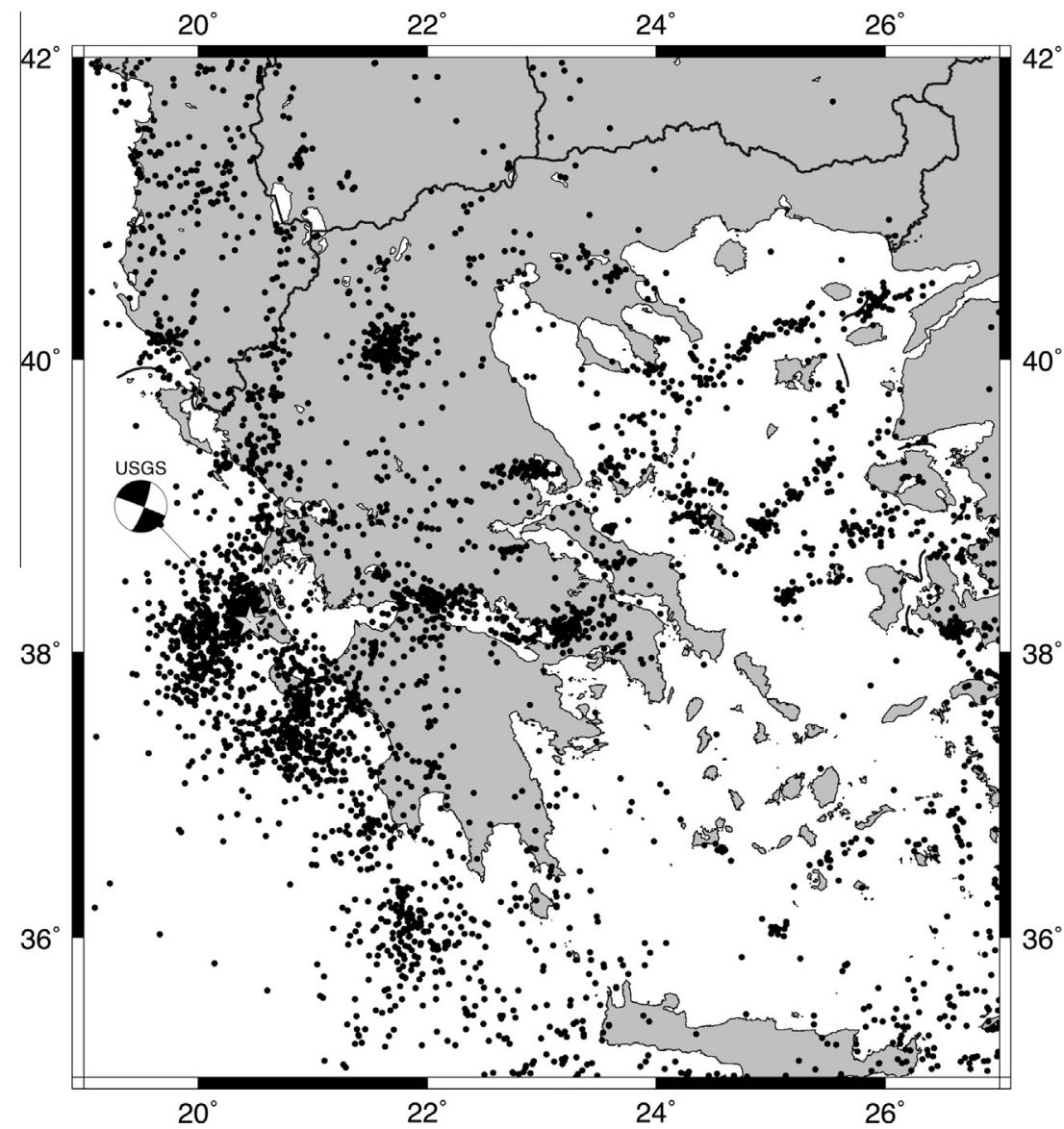

Fig. 1. Global seismicity $(M \geqslant 4.0)$ in Greece from 1980 to 2014 (USGS). Moment tensor solution for the 26 January 2014 earthquake is presented.

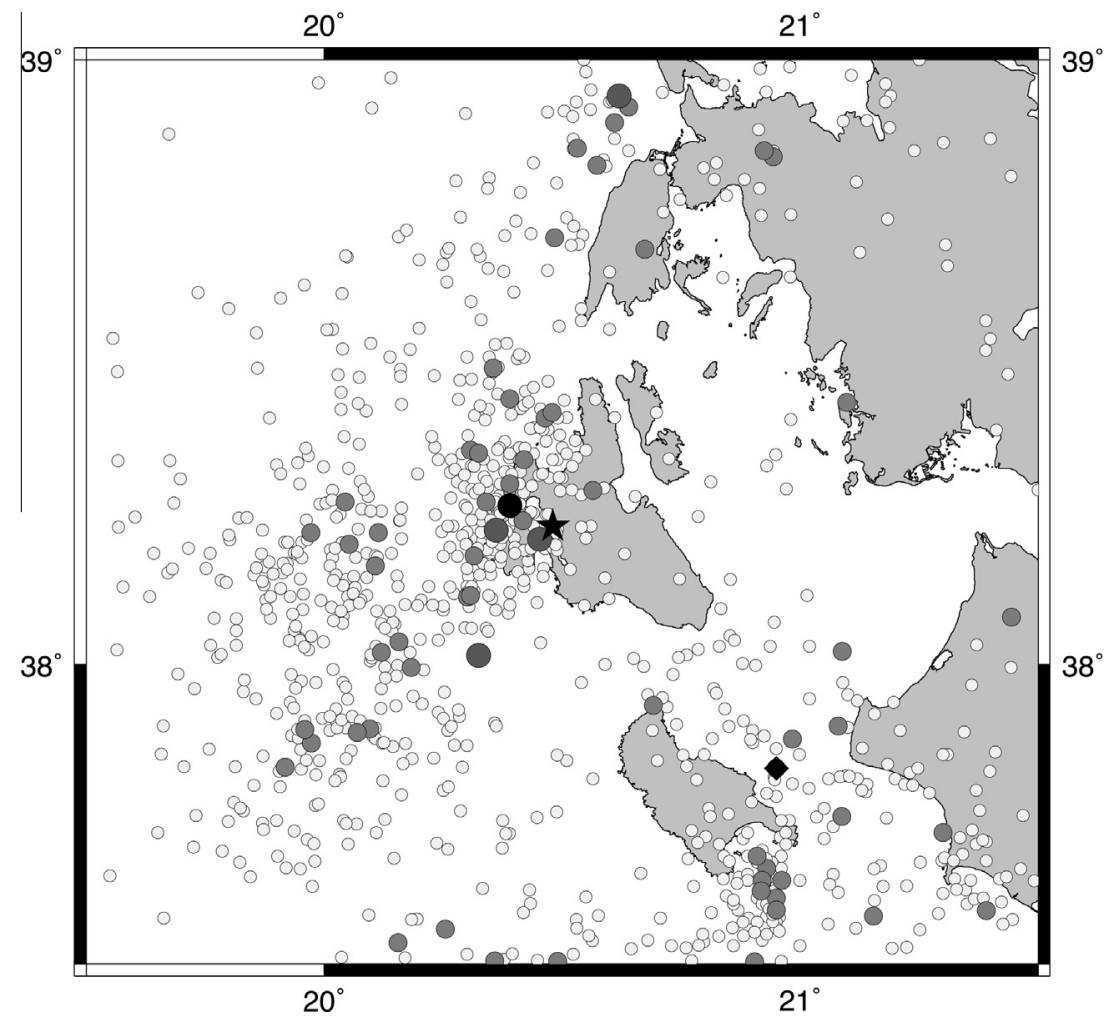

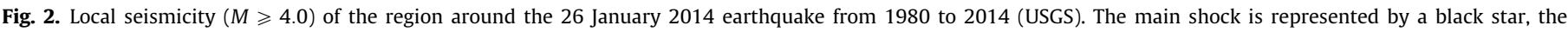
foreshock by a black diamond and the aftershock by a black circle.

Please cite this article in press as: Sanchez-Dulcet, F., et al. Analysis of observations backing up the existence of VLF and ionospheric TEC anomalies before the Mw6.1 earthquake in Greece, January 26, 2014. J. Phys. Chem. Earth (2015), http://dx.doi.org/10.1016/j.pce.2015.07.002 
(a) Seismicity from $2004-10-10$ to $2014-06-30$

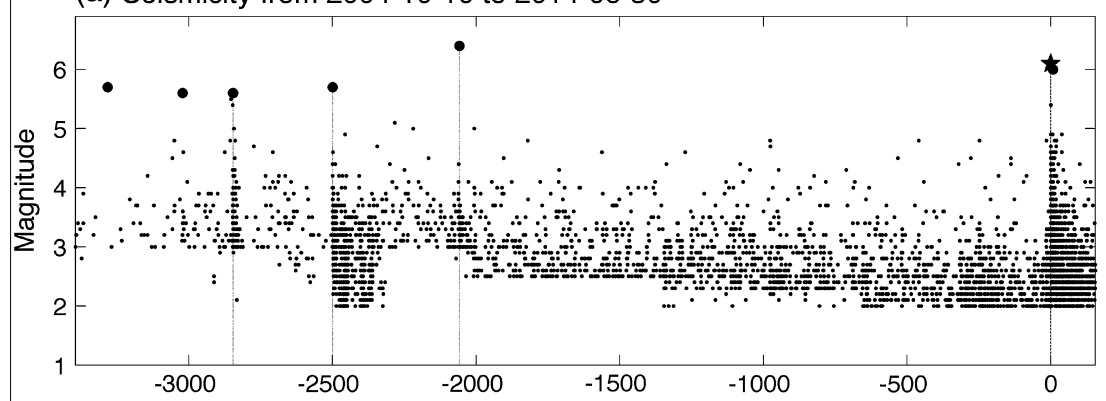

(b) Detail for the earthquake moment

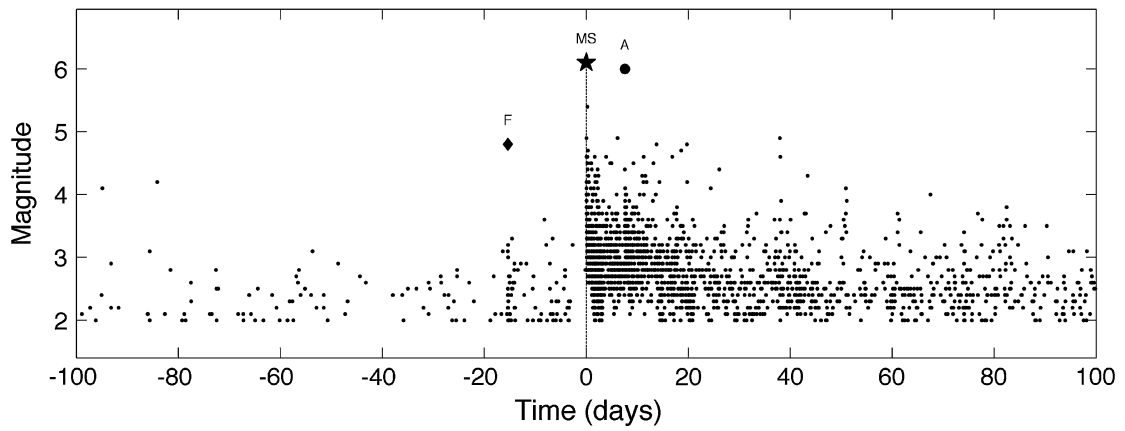

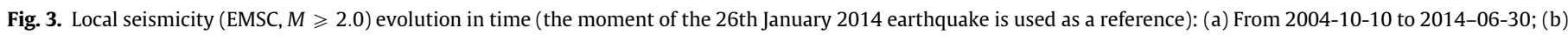
Close up around the earthquake.

\subsection{Geomagnetic conditions}

To ensure, at least to first approximation, that the anomalies presented in this paper were not caused by geomagnetic phenomena with global character, we studied the global geomagnetic indexes Dst (Disturbance storm time) and Kp (planetary threehourly $\mathrm{K}$ index). Dst is a measure of the decrease in the horizontal component of the Earth's magnetic field near the magnetic equator due to increases in the magnetospheric ring current. Values lower than -50 and -100 correspond to moderate and strong storms, respectively (González et al., 1994). The planetary 3-h-range index $\mathrm{Kp}$ is the mean standardized K-index from 13 geomagnetic observatories at median geomagnetic latitudes. The K-index is a quasilogarithmic local index of the 3-hourly range that quantifies the disturbance of the horizontal component of the geomagnetic field. The value of the two indexes has been obtained from World Data Center for Geomagnetism, Kyoto (wdc.kugi.kyoto-u.ac.jp). We also analysed the behaviour of the magnetic field in two observatories in the study region; Pedeli, Greece $\left(51.90^{\circ} \mathrm{N}, 23.90^{\circ} \mathrm{E}\right)$ and Ebre, Spain $\left(49.18^{\circ} \mathrm{N}, 0.49^{\circ} \mathrm{E}\right)$ chosen to compare the geomagnetic conditions close and far from the epicentre. This information was taken from the Intermagnet website (www.intermagnet.org).

In Fig. 4 (top), the Dst index values in the period from 45 days before the day of the earthquake (considered day 'zero') to 30 days after it are shown. The horizontal axis represents the days and the origin corresponds to 00:00 UT of the day of the earthquake. The vertical discontinuous line marks the earthquake occurrence time. The Dst index remains above $-50 \mathrm{nT}$, until day +24 (February 19th) when drops to $-112 \mathrm{nT}$, a value that, as stated previously, indicates the presence of an intense geomagnetic storm. Therefore, in the days of the analyses (from -25 to +10 ), the Dst index does not show a global geomagnetic disturbance. To validate this observation, we also show the three-hourly index Kp during this period (Fig. 4 bottom). The $x$-axis is measured in days and spans from 25 days before the earthquake until 10 days after it. As previously stated, the vertical discontinuous line marks the earthquake occurrence time. Only Kp values higher than 5 (on a logarithmic scale from 0 to 9 ) indicate the presence of geomagnetic disturbances. For our period of interest, these values are not reached at any time, so we can ensure that in the days analysed the global geomagnetic conditions are quite.

The analysis of the total geomagnetic field, $F$ in Ebre and Pedeli is shown in Fig. 5, which displays the values of the variation of $F$ (nT) per minute in the days of study. As in the preceding figure, the $x$-axis marks the 35 days considered and the vertical discontinuous line indicates the earthquake occurrence time. In this period, no strong fluctuations of the geomagnetic field are observed at any moment.

\subsection{Solar emission conditions}

Solar activity can affect the ionosphere even without having a clear effect on the geomagnetic conditions. Sudden increases in the solar ultraviolet emissions and X-ray flux can influence the photoionization processes modifying both the electron density in the ionosphere and the propagation parameter of VLF. Thus, a detailed analysis of the solar influence in the period considered has been taken by considering the occurrence of solar flares, the evolution of the F 10.7 index and the presence of Sudden Ionospheric Disturbances, SIDs.

NASA reports indicate the occurrence of only four important solar flares in this period with values of M9 on 1st January, X1 on 7th January, M8 on 30th January and M6 on 1st February. Only the X1 solar flare had a significant magnetic effect on the Earth. The variation of the F10.7 index, which correlates with the ultraviolet emissions, reflects this situation and shows that there was not any event that was able to affect the ionospheric conditions in the period analysed (Fig. 6 left). SIDs appear when the ionization in the D layer increases due to hard X-rays and UV radiation that originated from solar flares. This phenomenon can increase both the radio-wave absorption in the upper MF $(300 \mathrm{kHz}-3 \mathrm{MHz})$ and lower $\mathrm{HF}(3-30 \mathrm{MHz})$ ranges, and the reflection coefficient of VLF 

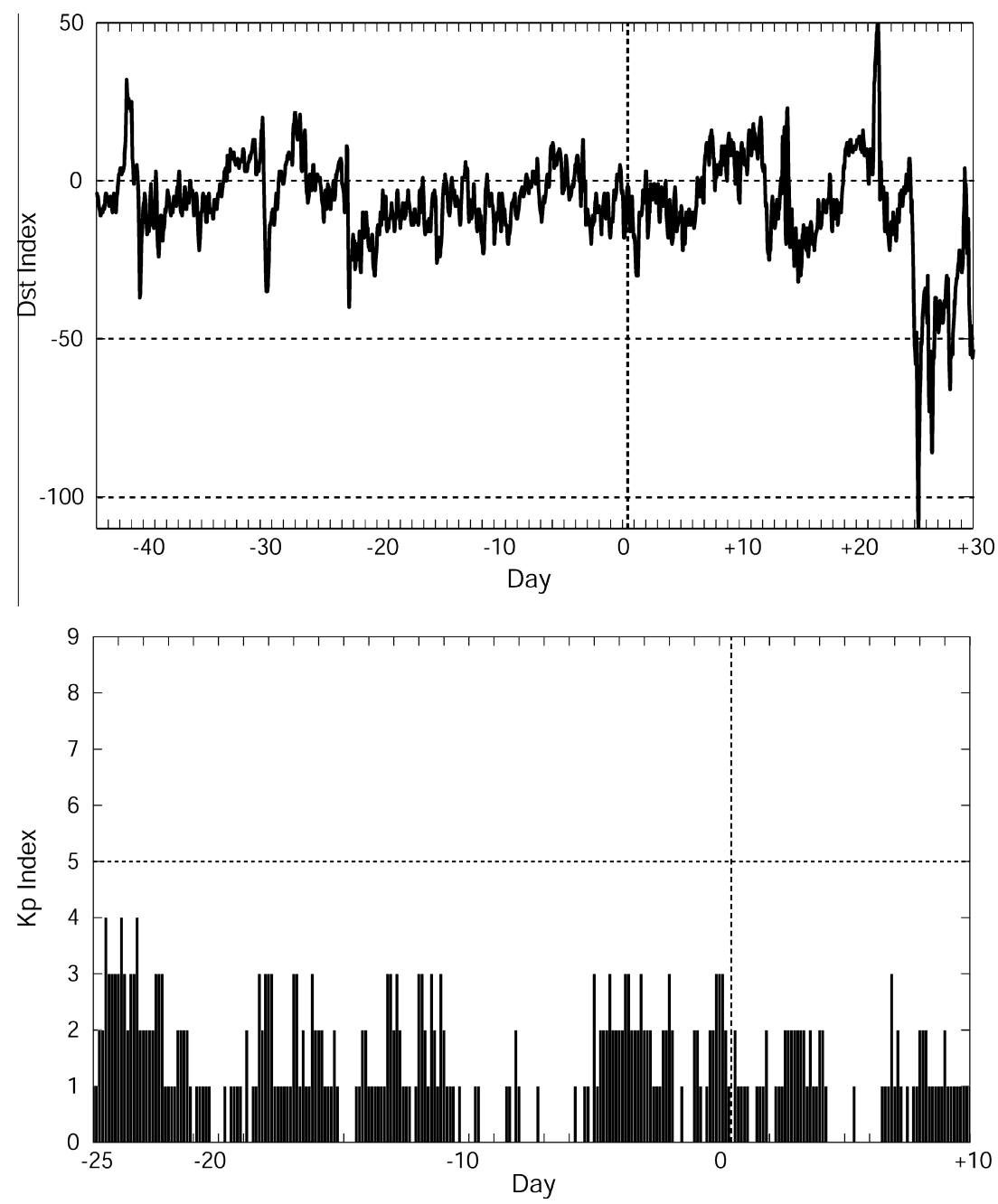

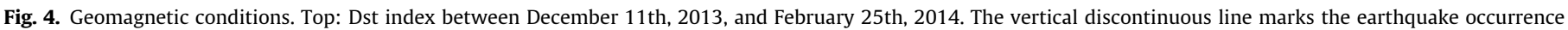
time. Bottom: Kp index between January 1st and February 5th, 2014. The vertical discontinuous line marks the earthquake occurrence time.

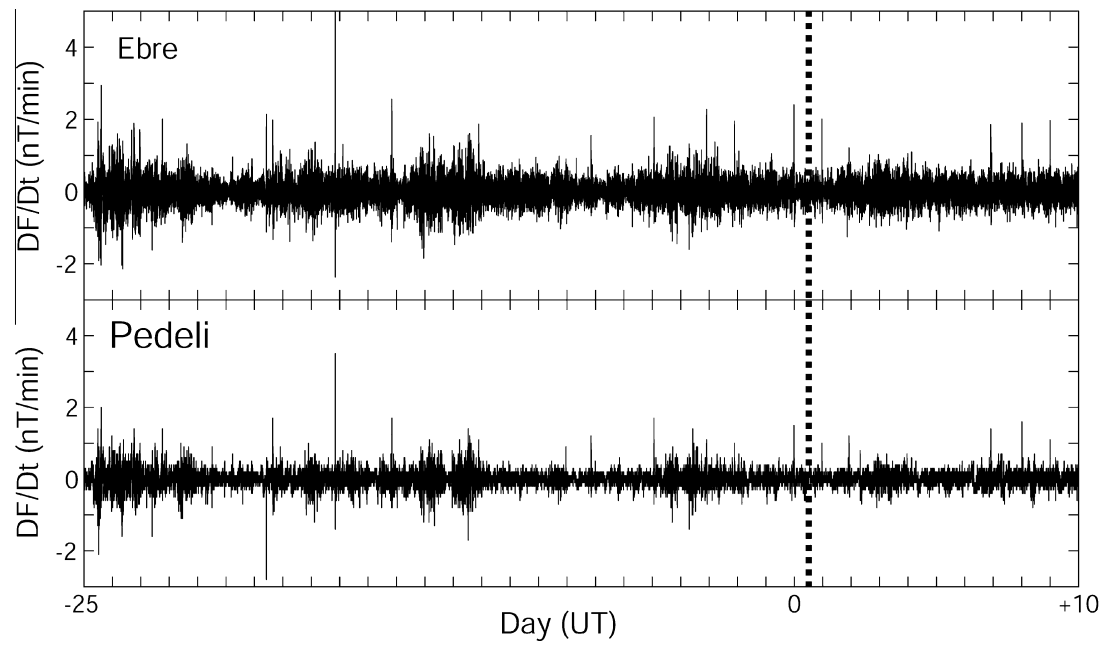

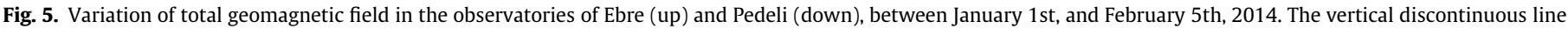
marks the earthquake occurrence time.

signals. Fig. 6 (right) plots the number of SIDs that occurred in the period of study given by the American Association of Variable Star Observers (AAVSO), the organization that provides NOAA (National
Oceanic and Atmospheric Administration) with this type of information. The total number of SIDs recorded in January was 288 and all, except for 6 , were events of small to moderate intensity. 

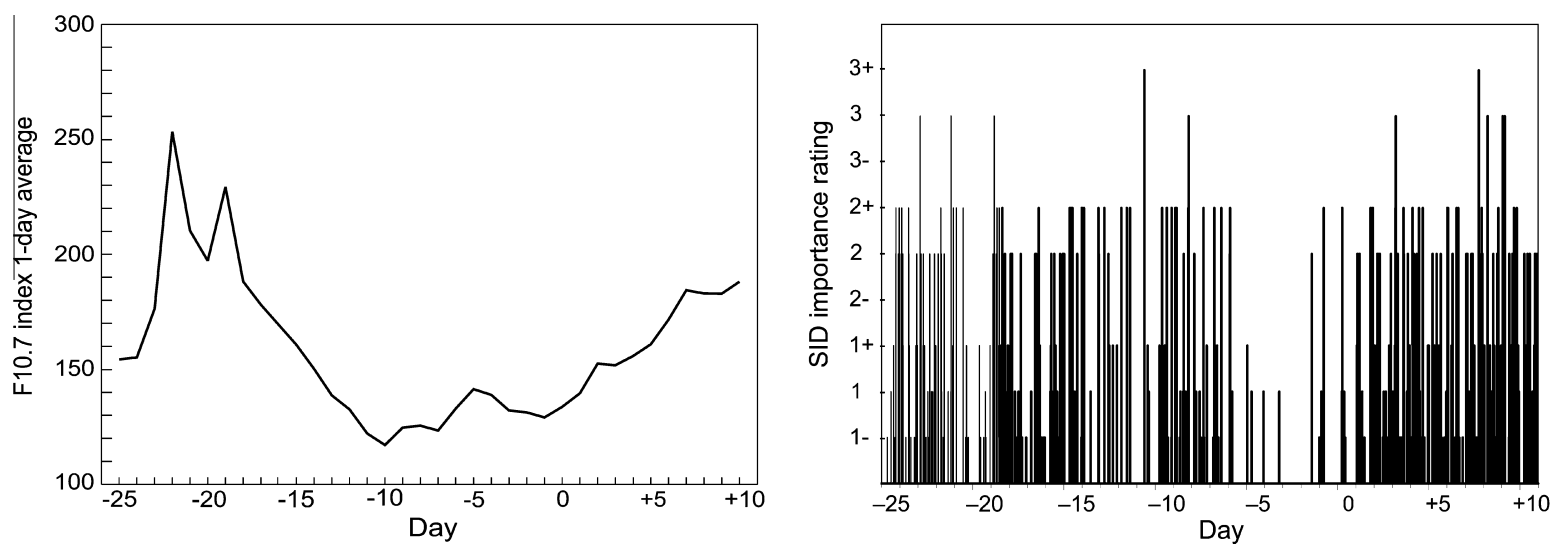

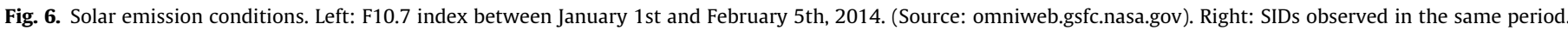

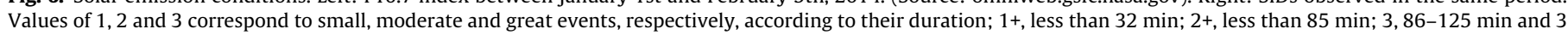
+ , more than $125 \mathrm{~min}$. (Source:www.aavso.org/sid-database).

It is worth noting the low number of SIDs in the days preceding the earthquake.

The analysis of this information allows us to consider our period of study free of important solar influences that could significantly contaminate our results.

\subsection{Meteorological conditions}

The meteorological conditions have different influences on VLF radio transmissions and on TEC values. In the first case, they are a key factor because they can induce anomalies that can be confused with those caused by earthquake precursor phenomena. In fact, Rozhnoi et al. (2014) studied the effects of tropical cyclones on the transmission of VLF/LF signals, revealing a strong correlation between the meteorological impact of the cyclones and perturbations in the VLF/LF signals; these signals are actually used for thunderstorm mapping (Mezentsev and Füllekrug, 2013). Inspection of the weather conditions is necessary to avoid "meteorological contamination" of the analysis presented here. Surface weather information for the epicentral area and the regions where the VLF radio receivers considered in this work are located was retrieved from the Russian Weather website: http://rp5.ru/. The locations studied are Chania (Crete), Thessaloniki (Greece) and Évora (Portugal). Thessaloniki station is the closest to the earthquake epicentre; thus, it can be interpreted as representative of the weather conditions there. The earthquake occurrence time is set as "zero time" and, as stated above, the period considered goes from January $1 \mathrm{st}$ until February 5th of 2014. Two main meteorological parameters (pressure and wind speed) are presented for the three locations in Fig. 7. It can be seen that both Chania and Thessaloniki have similar weather trends. That is, they show sizeable depressions (Fig. 7a and b) and high wind speeds (Fig. $7 d$ and e) close to the time of the earthquake. In the case of Chania, this is also accompanied by thunderstorm activity and, in Thessaloniki, complemented by moderate to high precipitation. This could represent a contamination of radio signals received at these stations. As shown in Fig. $7 \mathrm{c}$ and $\mathrm{f}$ in the case of Évora no particular feature in the time of the earthquake was observed. Thus, the signals received at this location can be used as a good reference for the signals expected to be affected by the earthquake.

In the case of TEC values, severe meteorological events, such as cyclones, typhoons, tornadoes, and hurricanes, are able to generate Internal Atmospheric Waves in the lower atmosphere that, under favourable conditions, can penetrate into the ionosphere and create electron density disturbances (Kazimirovsky, 2002; Kazimirovsky et al., 2003). First studied by Bauer (1958), this subject is a particular case for the links between the ionosphere and the lower atmosphere (Rishbeth, 2006; Lastovicka, 2006) and has received increasing attention, mainly in the case of strong events that occur at tropical latitudes (Bishop et al., 2006; Afraimovic et al., 2008; Perevalova and Ishin, 2011). Although the influence of strong meteorological storms at mid latitudes is not well known, it seems that only cyclonic events characterized by wind speeds greater than $33 \mathrm{~m} / \mathrm{s}$ induce noticeable effects on the ionosphere (Polyakova and Perevalova, 2013). As the meteorological storm that occurred over Crete only reached $11 \mathrm{~m} / \mathrm{s}$ of wind speed, it is possible to assume that it did not produce any significant disturbance on the TEC.

\section{Analysis of the VLF radio transmissions}

We begin the analysis of the ionosphere perturbations possibly linked with the occurrence of the January 26, 2014, earthquake in Greece by analysing VLF radio signals as explained below. The radio receivers used in this study are marked with triangles, and the VLF transmitters by black diamonds in Fig. 8. In this figure the GPS stations used to study the spatial distribution of the ionospheric anomaly related to the January 2014 seismic events are also represented. The earthquake epicentre is marked with a star.

\subsection{Data}

VLF radio transmissions were recorded at 1-min intervals by three receivers at Chania (Crete, CRE), Thessaloniki (Greece, GRE), and Évora (Portugal, POR). These receivers integrate the International Network for Frontier Research on Earthquake Precursors, INFREP (Biagi et al., 2011) especially prepared for the study of ionosphere earthquake precursors. Signals emitted during the time of study by four European transmitters, listed in Table 1, were considered. Moreover, following the Dobrovolsky formula, (Dobrovolsky et al., 1979), an M6.1 earthquake would have a preparation radius of nearly $420 \mathrm{~km}$. Thus, the CRE receiver is installed approximately $440 \mathrm{~km}$ from the earthquake epicentre, near to the limit of the earthquake preparation zone. The GRE receiver is approximately $350 \mathrm{~km}$ from the epicentre inside this region, and the POR receiver is located fairly far from the earthquake epicentre, nearly $2500 \mathrm{~km}$, which is away from the preparation zone.

\subsection{Methodology}

To follow the evolution of the VLF radio signals at the three receivers, we have represented the data time series, hourly 

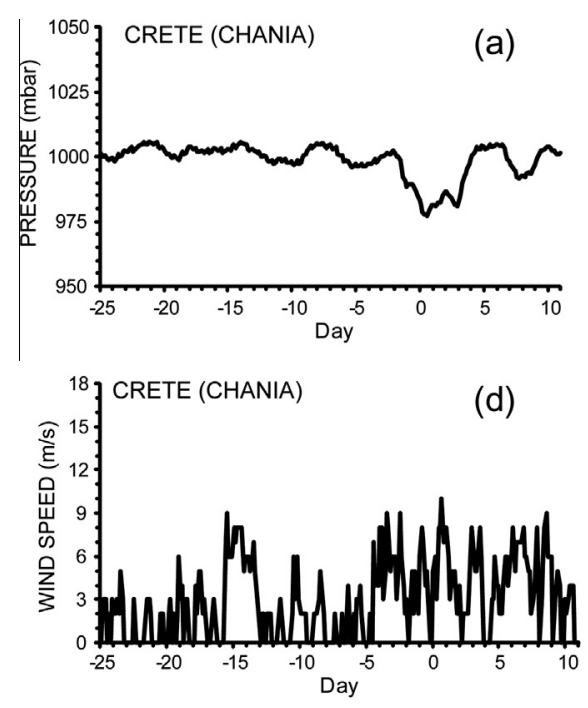
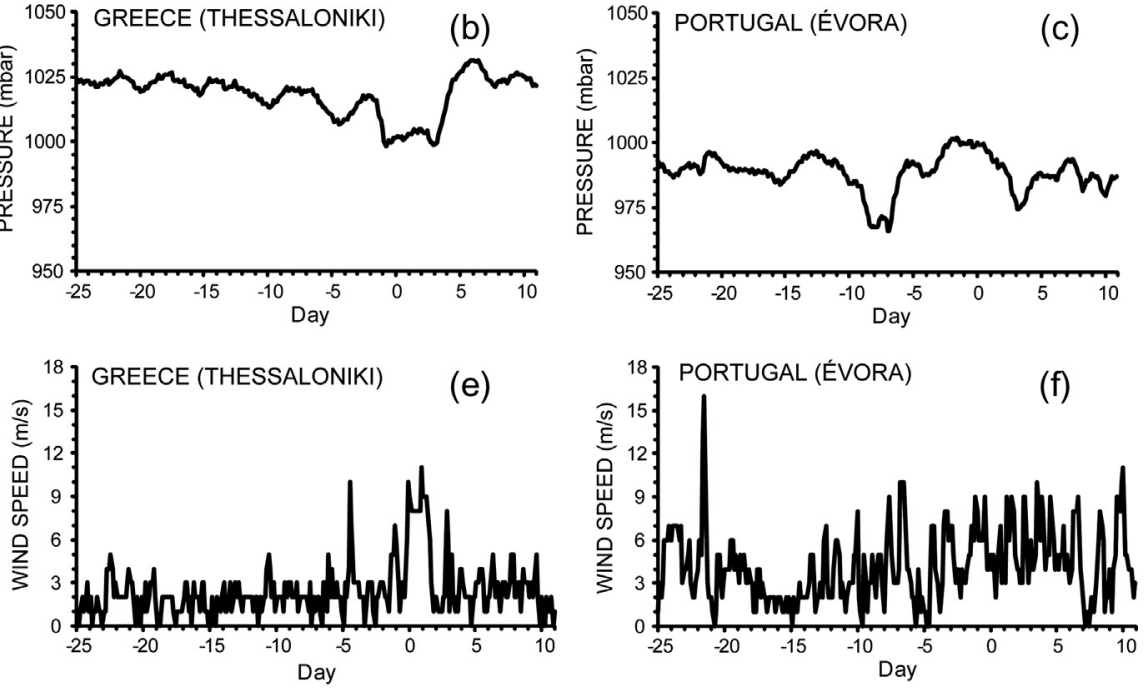

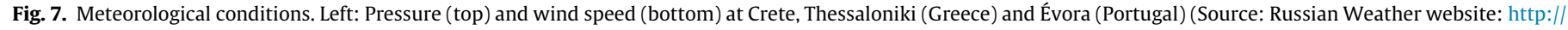
rp5.ru/).

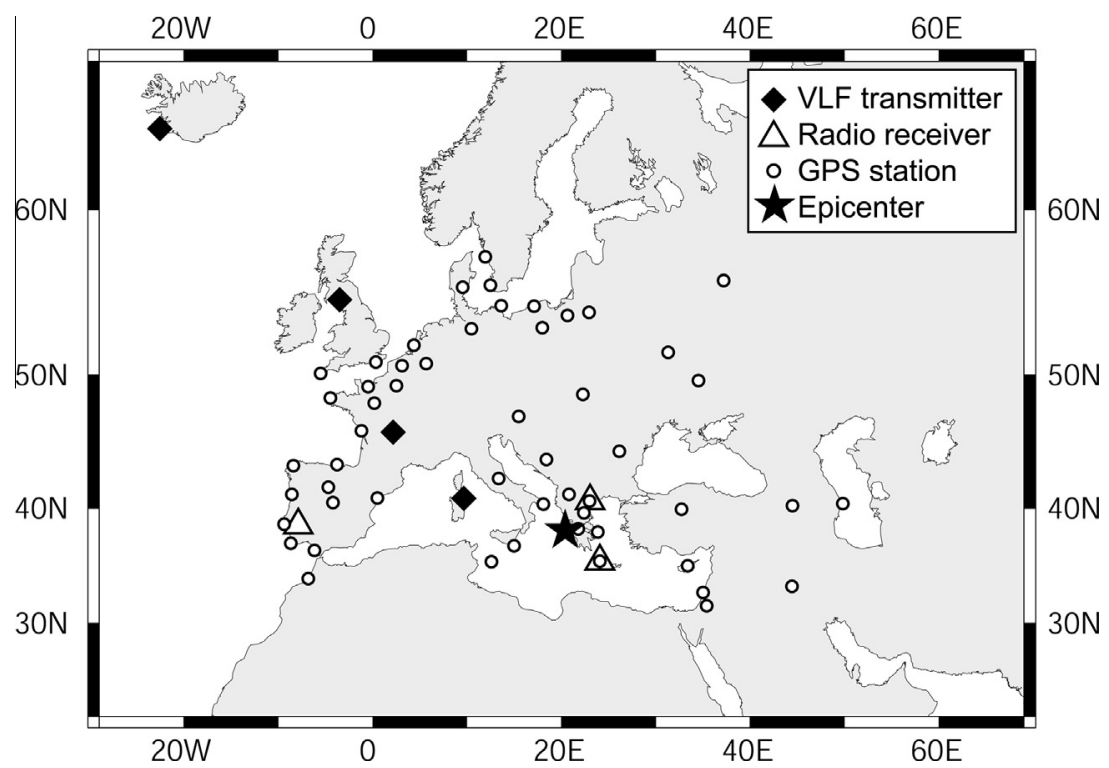

Fig. 8. Spatial distribution of GPS station, VLF transmitters and receivers. The earthquake epicentre is marked by a star.

Table 1

Main characteristics of the VLF transmitters used in the study: name, location, geographic coordinates and emission frequencies.

\begin{tabular}{llcll}
\hline Name & Location & $\begin{array}{l}\text { Longitude } \\
\left({ }^{\circ} \mathrm{E}\right)\end{array}$ & $\begin{array}{l}\text { Latitude } \\
\left({ }^{\circ} \mathrm{N}\right)\end{array}$ & $\begin{array}{l}\text { Frequencies } \\
(\mathrm{Hz})\end{array}$ \\
\hline NRK & Keflavik, Iceland & -22.57 & 64.02 & 37,500 \\
HWU & Le Blanc, France & 1.24 & 46.71 & $\begin{array}{l}20,900 \text { and } \\
21,750\end{array}$ \\
& & & & 20,270 \\
ICV & Tavolara, Italy & 9.71 & 40.91 & 19,580 \\
GBZ & Anthorn, Geat Britain & -3.28 & 54.91 &
\end{tabular}

variance and the corresponding wavelets for each station (Fig. 9-12). The hourly variance is normalized to its mean value in the period considered. It closely reflects the impulsivity parameter (Saha et al., 2014). The wavelet technique is widely used in many sciences such as Meteorology and Oceanography (Meyers et al., 1993), image processing (Chen and Shen, 2005) and solar physics (Lopes and Silva, 2015) to look for periodicities and inspect their evolution. In the present analysis we consider periods between 2.2 days and 6.2 days. This range has been specifically chosen to avoid the influence of two main cycles in the wavelet spectra. The first one is an approximately 1-day cycle of the lower ionosphere caused by the daily variation of the solar radiation and, to a lesser extent, by anthropogenic pollution, both atmospheric and electromagnetic. This procedure avoids the use of the common approach of separating day-time and night-time signals to perform the wavelet analysis. Actually, if the wavelet analysis is performed with the complete data set without filtering to periods longer than the daily cycle, this cycle will dominate the wavelet spectra, and any anomaly would hardly be noticed. The second cycle to be avoided is a close to 7-day cycle that dominates the electrical behaviour of the lower atmosphere due to urban pollution (Silva et al., 2014) and can also contaminate the wavelet spectra. This cycle is of particular importance because electromagnetic contamination caused by anthropogenic activity, for example, air conditioning systems near the radio receiver, are likely to contaminate the radio signals with a weekly cycle as they are used on work days but not on weekends. 

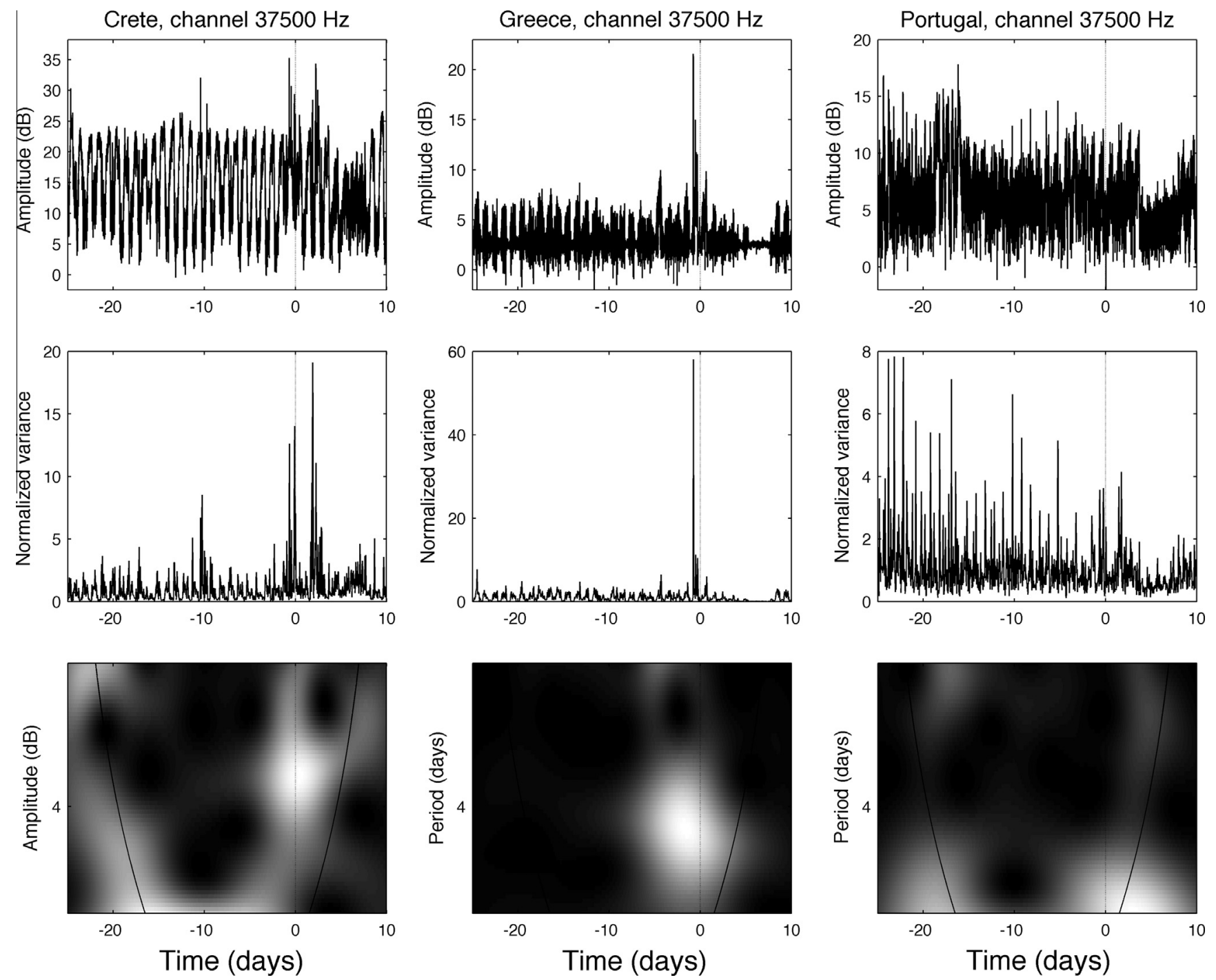

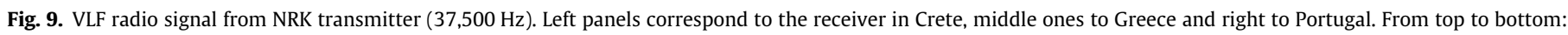
raw data, normalized daily variance and wavelet Morlet transform. The January 26, 2014 earthquake is time zero.

In the calculations, we use a MatLab ${ }^{\circledR}$ implementation of the wavelet algorithm developed by Torrence and Compo (1998). We chose the Morlet wavelet, and we padded the time series with zeros according to the mentioned script. The following parameters were used: $d t=1 / 1440 ; d_{j}=0.025 ; s_{0}=0.5 d t$; and $j_{1}=16 / d_{j}$. Finally, we standardize the VLF time series, $V L F_{S}(t)=$ $\left(V L F(t)-V L F_{m}\right) / \sigma_{V L F}$, where the $V L F(t)$ is the VLF radio signal collected every minute and $V L F_{m}$ and $\sigma_{V L F}$, respectively, are the average value and the standard deviation for all of the time series. This procedure centres and normalizes the data series but, as will be discussed below, differs from the technique used in $T E C *$ Sigma where a moving standardization is adopted.

\subsection{Results}

The results are discussed for each of the four transmitted signals:

(1) Signals from NRK $(37,500 \mathrm{~Hz})$ are plotted in Fig. 9 and show clear anomalies at the CRE and GRE receivers. Spikes appear in the records of these receivers approximately 1 day before the seismic event. Nevertheless, the perturbation is more pronounced in GRE where the hourly variance reaches a value 60 times higher than the mean hourly variance. This is consistent with the fact that this receiver is closer to the earthquake epicentre than CRE. The signal that reaches the two receivers is inside the 5th Fresnel zone (Righetti et al., 2012) and also reveals anomalous periods ( $\sim$ days) in the wavelet analysis, nearly at the same moment as the observed spikes. The signal received by POR is outside the 5th Fresnel zone and does not present any anomaly in the signal or in the wavelet that could be possibly related to the earthquake, as it is expected.

(2) The results for the signals broadcast by $\operatorname{HWU}(20,900 \mathrm{~Hz}$ and $21,750 \mathrm{~Hz}$ ) are represented in Fig. 10, which shows that the signal received by POR (outside the 5 th Fresnel zone) does not present any anomaly that could be linkable with the earthquake. Moreover, the receiver at CRE shows two spikes, the first $\sim 1$ day before and the other nearly 2 days after the earthquake, that are reflected in two spikes in the normalized variance. The signal recorded in GRE does not show any spike in the normalized variance but presents an anomalous period close to 4 days in the wavelet spectra. The results are not so clear for this transmission and could be related to the meteorological condition both in Chania (CRE) and Thessaloniki (GRE). 

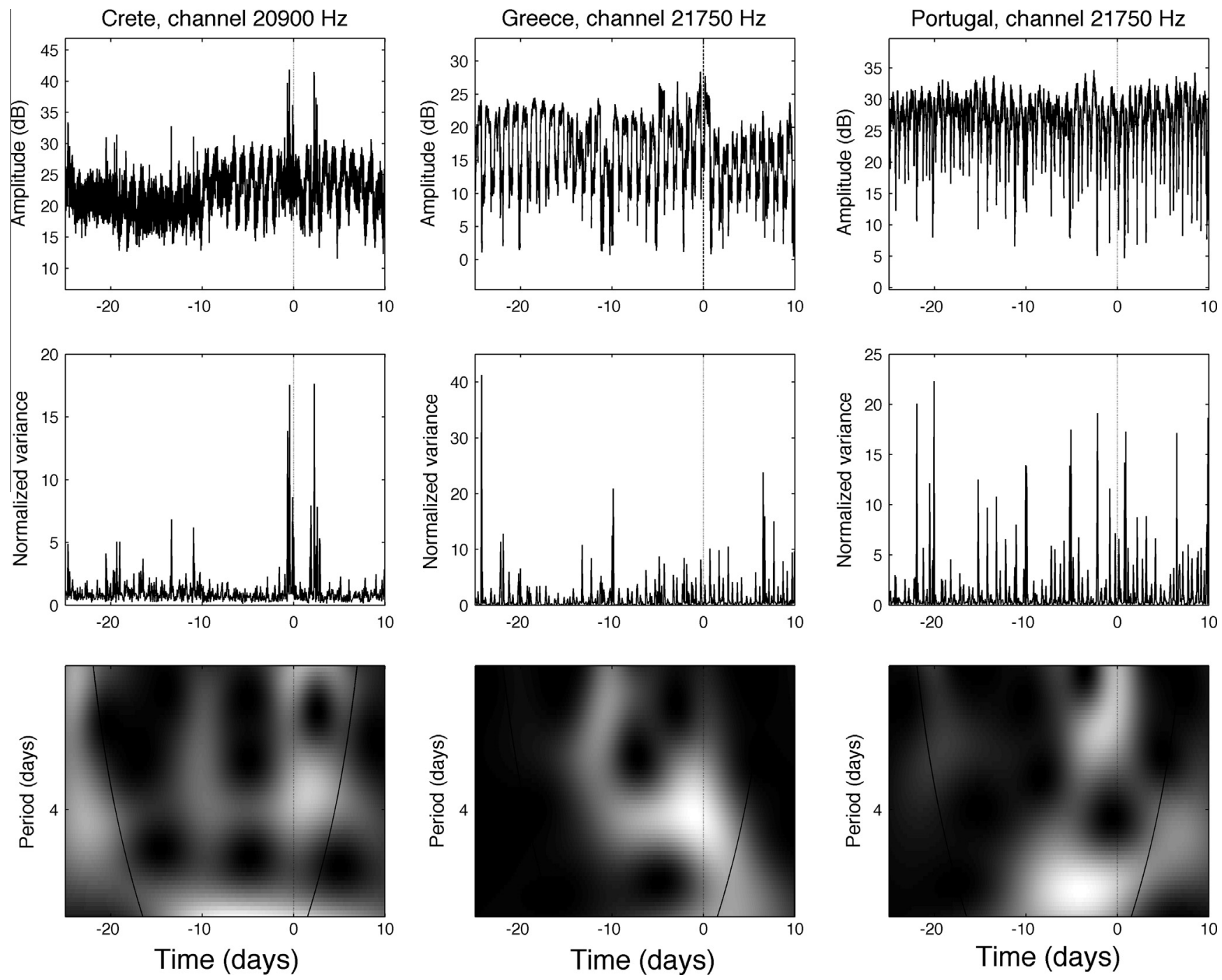

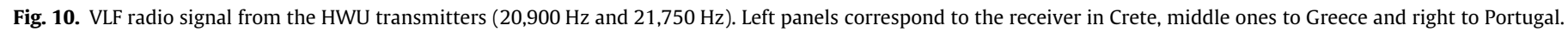
From top to bottom: raw data, normalized daily variance and wavelet Morlet transform. The January 26, 2014 earthquake is time zero.

(3) The signals transmitted from ICV $(20,270 \mathrm{~Hz})$, shown in Fig. 11, present evidence of an anomalous behaviour of the hourly variance for the signal collected at CRE that reached 20 times the mean value of the period on the day before the earthquake. An approximately 4-day anomaly is evident in the wavelet analysis of the GRE signal. Moreover, the reduction of CRE and GRE 20 days before the earthquake and 3 days after could be related to the seismic event, but no data from a reference receiver outside the 5th Fresnel zone, such as POR, exists to confirm it. Similar behaviour to HWU but less significant was found for this transmitter (both have similar frequencies), and again, it is argued that the signal could have been affected by the meteorological conditions.

(4) The signals broadcast by GBZ $(19,580 \mathrm{~Hz})$ are shown in Fig. 12 and indicate that the GRE signal also has an approximately 4-day anomaly in the wavelet spectra. In contrast, nothing is seen in the POR signal. These findings are in accordance with those obtained for the previous frequencies.

\section{TEC analysis}

The ionospheric parameter used on this part of the study is the total electron content, TEC, which can be defined as the integral of the electron density along a path between two points, usually a GNSS receptor on Earth's surface and a satellite. TEC can also be defined as the number of free electrons contained in a column with a cross-section of one square metre. One TEC unit (TECu) corresponds to $10^{16}$ electrons per $\mathrm{m}^{2}$. This parameter can be obtained by measuring the travel time difference for two signals with different frequencies, $f_{1}$ and $f_{2}$, along the same propagation path in the ionosphere. When using the GPS network, the receivers generate two observable delays for each satellite: pseudo-range delay and carrier phase delay. The frequency-differenced phase delays provide very precise measurements of TEC (Mannucci et al., 1998). These data are available in RINEX (Receiver Independent Exchange Format) files that, in our case, have been processed using a technique developed by Ciraolo et al. (2007) that considers the ionosphere as a thin shell located at an altitude of $350 \mathrm{~km}$ (high of the maximum of F2 layer) where all of the free electrons are concentrated. This technique determines the vertical total electron content, $v T E C$ (TEC in a vertical column over the receiver) from slant total electron content, STEC, (TEC in the path between the receiver and the satellite) at the Ionospheric Pierce Point, IPP. This point corresponds to the place where the line-of-sight between the satellite and ground receiver intersects the ionosphere, which is considered as a thin shell. 

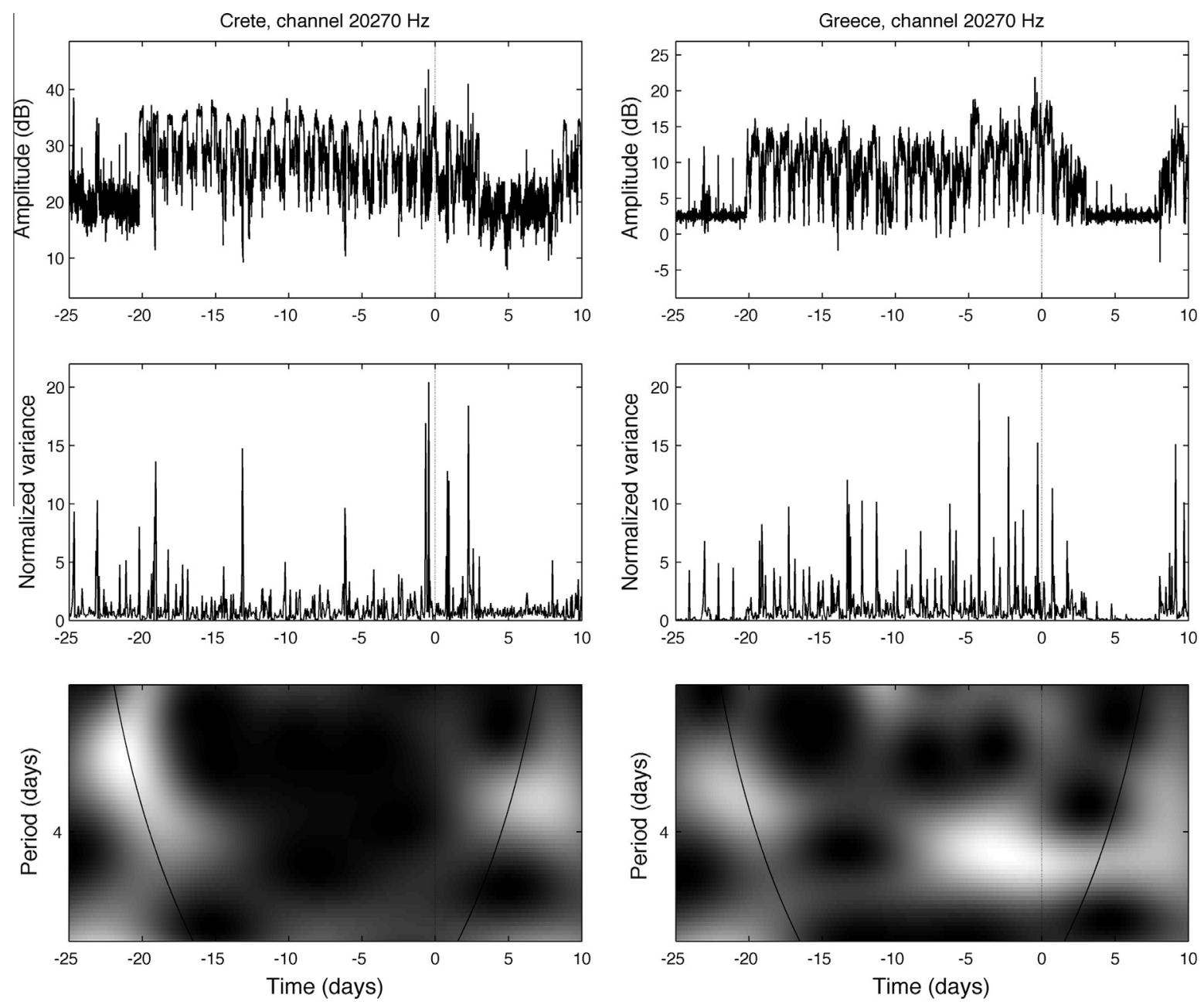

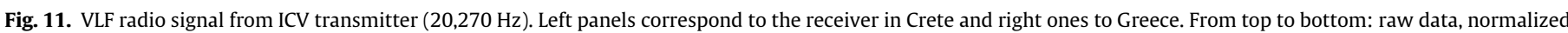
daily variance and wavelet Morlet transform. The January 26, 2014 earthquake is time zero.

\subsection{Methodology: TEC*Sigma}

To quantify the temporal variations of $v T E C$ at every station, we used the TEC*Sigma parameter (Davidenko and Pulinets, 2012), which is given by the expression $T E C * \operatorname{Sigma}=\left(v T E C-T E C_{C P}\right) / \sigma$, where $v T E C$ is the observed value and $T E C_{C P}$ and $\sigma$, respectively, represent the mean value and the standard deviation of the $v T E C$ values obtained at the same time during the previous 15 days. $T E C *$ Sigma scales the $v T E C$ anomalies, i.e., the differences between the observed and the selected reference values. To perform this task, TEC*Sigma considers the ionospheric variability over every station during the analysed time divided by the standard deviation. In this way, the anomalies observed at different times and locations are normalized by the standard deviation.

The magnitude of the studied effects is revealed when the anomalies observed at different stations are compared with the usual temporal variability at each place. Only when the TEC*Sigma is the same at two different stations, no matter the absolute value of $V T E C$ variations, it is possible to state that both stations experiment the same ionospheric effect. With this in mind a $V T E C$ variation will be considered significant in this article when $T E C *$ Sigma $\geqslant \pm 2$. It is worth remembering that for a normal distribution, a $\pm 2 \sigma$-wide band centred at the average contains $96 \%$ of the sample values. Although it is clear that the VTEC values collected at the same station and at the same time during the 15 days does not exactly adjust to a normal distribution, the limit values established here allow us to accept, at least in a first approach, that the probability of their exceeding this limit is only $4 \%$. The probability of occurrence drops to $0.16 \%$ for the same phenomenon at the next instant. Therefore, the mentioned limit values $T E C * \operatorname{Sigma}= \pm 2$ act, for the considered approximation degree, as indicator of significant enough $v T E C$ variations. As a consequence, TEC $*$ Sigma $\geqslant+2$ $(T E C *$ Sigma $\leqslant-2)$ values indicate positive (negative) $v T E C$ anomalies; meanwhile, intermediate values $(-2<T E C * \operatorname{Sigma}<+2)$ indicate that these $V T E C$ variations fall inside the normal variability range and cannot be considered anomalies.

Fig. 13 illustrates the concepts exposed so far. In the upper panel, the thick trace shows the $V T E C$ evolution at the station closest to the epicentre (PAT0 station) during the interval going from the 2nd day before the earthquake ( -2 day) to the end of the occurrence day ( 0 day). The bottom continuous curve indicates the evolution of the standard deviation $\sigma$. The mean value $T E C_{C P}$ is shown with a broken line and the limits corresponding to $T E C_{C P} \pm 2 \sigma$ are indicated with a dotted line. In the bottom panel the continuous trace shows the TEC*Sigma evolution. The values $T E C *$ Sigma $=0$ (equivalent to $v T E C=T E C_{C P}$ ) and $T E C *$ Sigma $= \pm 2$ (equivalent to $v T E C=T E C_{C P} \pm 2 \sigma$ ) are shown with a broken line and dotted line, respectively, as in the graph above. The limits for $T E C *$ Sigma $= \pm 2$ separate the normal values from the anomalous ones. In both graphs, the temporal resolution is 1 data point every $30 \mathrm{~min}$. The arrows indicate the more significant occasions in which these limits are exceeded during the day before the earth- 
Greece, channel $19580 \mathrm{~Hz}$
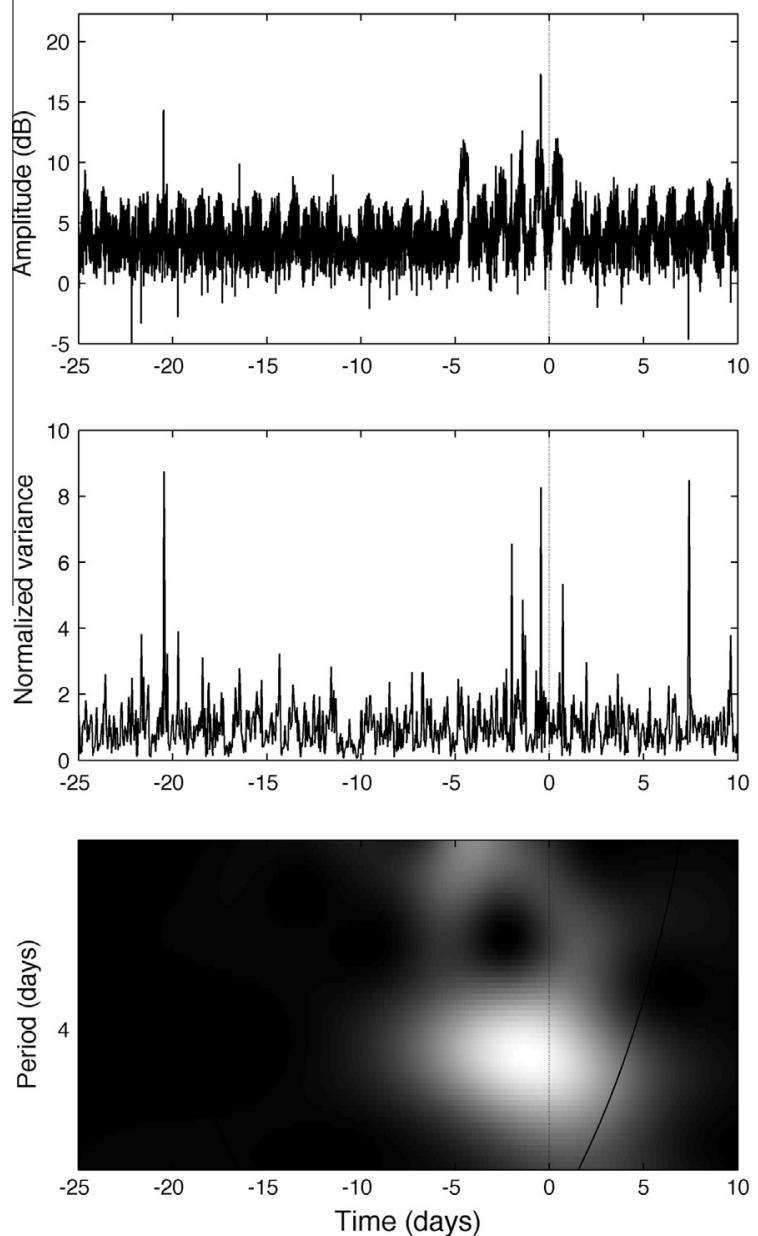

Portugal, channel $19600 \mathrm{~Hz}$
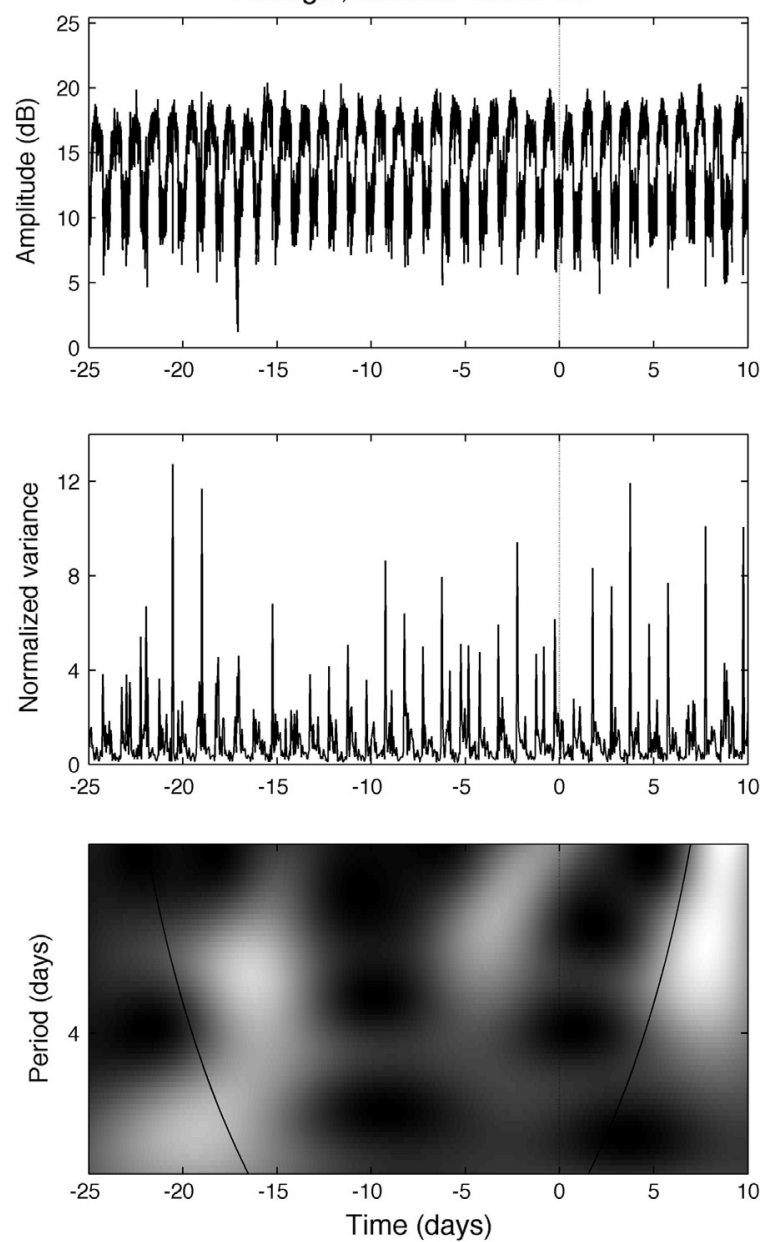

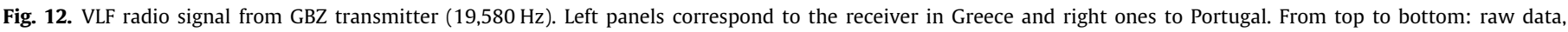
normalized daily variance and wavelet Morlet transform. The January 26, 2014 earthquake is time zero.

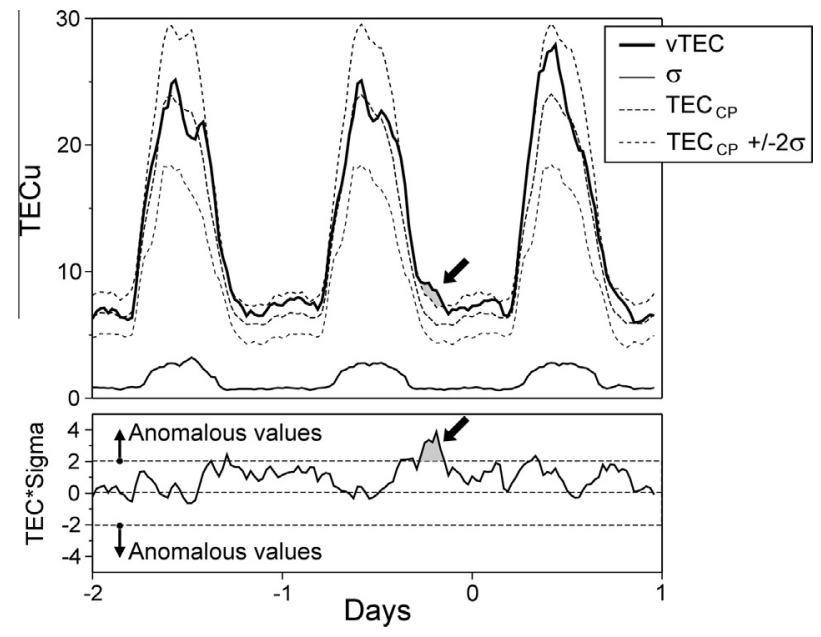

Fig. 13. In the upper panel, the thick trace shows the $V T E C$ evolution at the nearest station to the epicentre (PAT0 station). The mean value $T E C_{C P}$ is indicated by a broken line and the limits corresponding to $T E C_{C P} \pm 2 \sigma$ by a dotted line. In the bottom panel, the continuous trace shows the TEC*Sigma evolution. The values $T E C *$ Sigma $=0$ and $T E C *$ Sigma $= \pm 2$ are shown with a broken line and a dotted line. The limits for TEC $*$ Sigma $= \pm 2$ separate the normal values from the anomalous ones. The arrows indicate the more significant occasions in which these limits are exceeded during the day before the earthquake ( -1 day). Therefore, the presence of anomalous values of TEC $*$ Sigma indicates the presence of $v T E C$ anomalies. quake ( -1 day). Therefore, the presence of anomalous values of $T E C *$ Sigma means the presence of $v T E C$ anomalies.

It is worth remarking that the TEC*Sigma values are qualified as "anomalous" because they exceed the adopted limits; that is, they do not have the same meaning as the usual concept of "anomaly". The use of anomalous does not indicate a difference between the observed and reference values but instead the presence of a real $\checkmark T E C$ anomalies. In other words, we can say that every variation of $v T E C$ implies an anomaly of this parameter, and after normalizing this anomaly by the corresponding standard deviation, we obtain the TEC *Sigma value. When this value exceeds the adopted limits, it must be considered as "anomalous".

\subsection{GPS data}

The RINEX files analysed have been obtained from 53 stations belonging to International GNSS Service (IGS), EUREF Permanent Network (EPN) and University NAVSTAR Consortium (UNAVCO) GNSS networks. Their location is represented with circles in Fig. 8 and their main characteristics (name, geographic coordinates, network to which they belong and epicentral distance) can be found in Table 2 .

Most of the stations (47) were selected from a large sample of 90 receivers after checking the availability of continuous $V T E C$ records in a period ranging between 25 days before the earthquake and 10 days after its occurrence. In this way, by taking into account 
the need for data from 15 days to obtain TEC*Sigma, it was possible to study the evolution of this parameter for 21 consecutive days starting 10 days before the earthquake. Five other stations with shorter TEC*Sigma series were used to solve some graphical uncertainties when drawing the initial isovalues maps that are shown below. These stations are UZHL (data series starts on day -9), DRAG (data starts on day -6), LAMA and SASS (data starts on day -4) and ARUC (data series ends on day +1 ). Finally, station TUC2, whose data series spans days -9 to +3 , has been included in the analysis due to its proximity to the VLF receiver CRE.

\subsection{TEC results}

From top to the fourth row, Table 3 lists the considered day of the series, the number of stations with available TEC*Sigma data

\section{Table 2}

Main characteristics of the GPS stations used in the study: name, geographic coordinates, GNSS network they belong to, and epicentral distance.

\begin{tabular}{|c|c|c|c|c|}
\hline Name & Longitude $\left({ }^{\circ} \mathrm{E}\right)$ & Latitude $\left({ }^{\circ} \mathrm{N}\right)$ & GNSS Network $^{\mathrm{a}}$ & Distance $(\mathrm{km})$ \\
\hline PATO & 21.79 & 38.28 & 1 & 126 \\
\hline LARM & 22.39 & 39.61 & 1 & 239 \\
\hline NOA1 & 23.86 & 38.05 & 1 & 306 \\
\hline USAL & 18.11 & 40.33 & 1 & 310 \\
\hline ORID & 20.79 & 41.13 & $1,2,3$ & 333 \\
\hline AUT1 & 23.00 & 40.57 & 1 & 352 \\
\hline TUC2 & 24.07 & 35.53 & 1 & 440 \\
\hline NOT1 & 14.99 & 36.88 & $1,2,3$ & 494 \\
\hline SRJV & 18.41 & 43.87 & 1 & 657 \\
\hline LAMP & 12.61 & 35.50 & 1 & 750 \\
\hline AQUI & 13.35 & 42.37 & 1 & 757 \\
\hline BUCU & 26.13 & 44.46 & $1,2,3$ & 851 \\
\hline GRAZ & 15.49 & 47.07 & $1,2,3$ & 1068 \\
\hline ANKR & 32.76 & 39.89 & $1,2,3$ & 1088 \\
\hline UZHL & 22.30 & 48.63 & $1,2,3$ & 1176 \\
\hline NICO & 33.40 & 35.14 & $1,2,3$ & 1209 \\
\hline BSHM & 35.02 & 32.78 & 2,3 & 1454 \\
\hline DRAG & 35.39 & 31.59 & $1,2,3$ & 1776 \\
\hline BYDG & 17.99 & 53.13 & 1 & 1676 \\
\hline POLV & 34.54 & 49.60 & $1,2,3$ & 1701 \\
\hline CNIV & 31.31 & 51.52 & 1 & 1715 \\
\hline EBRE & 0.49 & 40.82 & $1,2,3$ & 1727 \\
\hline LAMA & 20.67 & 53.89 & $1,2,3$ & 1750 \\
\hline SWKI & 22.93 & 54.10 & 1 & 1784 \\
\hline EIJS & 5.68 & 50.76 & 1 & 1816 \\
\hline HOBU & 10.48 & 53.05 & 1 & 1822 \\
\hline REDZ & 17.12 & 54.47 & 1 & 1831 \\
\hline CREI & 2.51 & 49.26 & 1 & 1885 \\
\hline SASS & 13.64 & 54.51 & $1,2,3$ & 1889 \\
\hline LIL2 & 3.14 & 50.61 & 1 & 1938 \\
\hline MAN2 & 0.16 & 48.02 & 1 & 1964 \\
\hline ILDX & -1.18 & 46.01 & 1 & 1972 \\
\hline DELF & 4.39 & 51.99 & 1 & 1976 \\
\hline BUDP & 12.50 & 55.74 & 1 & 2042 \\
\hline CAEN & -0.46 & 49.18 & 1 & 2064 \\
\hline ARUC & 44.52 & 40.19 & 2,3 & 2089 \\
\hline SMID & 9.56 & 55.64 & 1 & 2105 \\
\hline CANT & -3.80 & 43.47 & 1 & 2109 \\
\hline HERT & 0.33 & 50.87 & $1,2,3$ & 2114 \\
\hline MAD2 & -4.25 & 40.43 & 2,3 & 2126 \\
\hline VALA & -4.71 & 41.70 & 1 & 2166 \\
\hline ONSA & 11.93 & 57.40 & $1,2,3$ & 2227 \\
\hline ISBA & 44.44 & 33.34 & 2 & 2231 \\
\hline BRST & -4.50 & 48.38 & $1,2,3$ & 2297 \\
\hline MDVJ & 37.21 & 56.02 & $1,2,3$ & 2347 \\
\hline ROAP & -6.21 & 36.46 & 2,3 & 2350 \\
\hline NEWL & -5.54 & 50.10 & 1 & 2438 \\
\hline ACOR & -8.40 & 43.36 & 1 & 2478 \\
\hline RABT & -6.85 & 34.00 & 1,2 & 2479 \\
\hline GAIA & -8.59 & 41.11 & 1 & 2489 \\
\hline BAKU & 49.81 & 40.37 & 2 & 2536 \\
\hline LAGO & -8.67 & 37.10 & 1 & 2549 \\
\hline CASC & -9.42 & 38.69 & 1 & 2584 \\
\hline
\end{tabular}

a GNSS Network: 1 EUREF Permanent Network (EPN), 2 University NAVSTAR Consortium (UNAVCO), and 3 International GNSS Service (IGS). for each day, the number of stations with $T E C_{*} \operatorname{Sigma} \geqslant \pm 2$ at any moment on that day and the corresponding percentage of this type of values. Rows five and six include the number of stations with $T E C *$ Sigma $\leqslant-2$ and the corresponding percentage of these values with respect to the total amount, respectively. This Table clearly shows that most stations present positive anomalous values of TEC*Sigma on days $-5,-4$ and -3 . In particular, this happens on day -4 at every station except POLV. It is also convenient to consider that the maximum value reached by the TEC*Sigma at this station is 1.9 , which is very close to the selected limit for normal values. Table 4 , which has the same distribution as Table 3 , shows the analogue results when only the 10 stations closest to the epicentre are considered. In this case, anomalous values are present in all of the stations not only on day -4 but also on days -1 and 0 .

The most remarkable negative anomalous values occur mainly on days -9 and -7 , regardless of if all of the stations or only the 10 closest to the epicentre are considered. In this last case, the relative proportion of affected stations on day -6 considerably increases with respect to the more general case. These differences are not significant for the other days.

The effects observed on day -4 spread over the entire area of study, while those occurring on days -1 and 0 were limited to the vicinity of the epicentre, suggesting that the positive anomalous $T E C_{*}$ Sigma values observed on those days could be associated with the earthquake preparation. As an example, Fig. 14 shows the differences between the EBRE (on the Spanish North Mediterranean coast, $1727 \mathrm{~km}$ from the epicentre) and PAT0 (126 km from the epicentre) stations. The figure shows the TEC *Sigma values at these stations during the 21-day interval considered in this analysis that includes 10 days before the earthquake and 10 days after it. As in the similar cases, the $\mathrm{x}$-axis is measured in days, and its origin corresponds to the 00:00 UT on the day of the earthquake, the vertical discontinuous line marks the earthquake occurrence time and the temporal resolution is 1 data point every $30 \mathrm{~min}$. The limits for TEC $*$ Sigma $= \pm 2$ separate the normal values (inside the grey band) from the anomalous ones. The arrows indicate the more significant positive anomalies on both days before the earthquake. At EBRE (far station), only the -4 day anomaly is observed. In contrast, at PAT0 (near station), anomalies appear on days -4 and -1 .

To confirm these results, maps of the anomalies for the significant hours on days $-4,-1$ and 0 were drawn. These maps plot the isolines corresponding to $T E C * \operatorname{Sigma} \geqslant+2$ with intervals of 0.5 and were sketched using the "pscontour" tool of the GMT package (Wessel and Smith, 1998). Fig. 15 shows the maps corresponding to 9 different hours of day -1 , where it is possible to observe a clear anomaly starting at 15:00 UT and lasting until 20:00 UT. The sunset at the longitude of the epicentre (marked with a star) took place at 15:53 UT. At 15:00 UT the maximum value of TEC*Sigma is 2.88 and occurs over the station TUC2, which is located in Crete Island, $440 \mathrm{~km}$ far from the epicentre. Later, the position of the highest value moves to the north and reaches 2.48 and 3.84 at 16:00 UT and 17:00 UT, respectively. Then, although values over 3 still remain to the north of the epicentre, the maximum $\left(T E C_{*}\right.$ Sigma $\left.=4.26\right)$ moves to the south and reaches the TUC2 station area. Finally, at 19:00 UT and 20:00 UT, the maximum successively occupies the regions over LARM $(T E C *$ Sigma $=3.62)$ and LAMP $(T E C *$ Sigma $=4.36)$, located 239 and $750 \mathrm{~km}$ far from the epicentre, respectively.

It is worth noticing several interesting features of these results. First, it is remarkable that the location of the maximum TEC *Sigma never corresponds to the closest station to the epicentre (PAT0, $126 \mathrm{~km}$ ) and that the smallest difference between these two points occurs at 19:00 UT, an intermediate moment of the evolution of the anomaly. Second, $T E C *$ Sigma reaches values greater than 4 on two occasions. The first time occurred at 18:00 UT in the 
Table 3

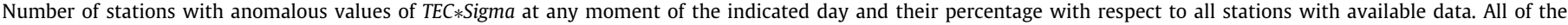
stations are considered.

\begin{tabular}{|c|c|c|c|c|c|c|c|c|c|c|c|}
\hline Day & -10 & -9 & -8 & -7 & -6 & -5 & -4 & -3 & -2 & -1 & 0 \\
\hline Number of stations with TEC $*$ Sigma & 48 & 50 & 50 & 50 & 51 & 51 & 53 & 53 & 53 & 53 & 53 \\
\hline Number of stations with TEC $*$ Sigma $\geqslant+2$ & 7 & 8 & 22 & 17 & 13 & 40 & 52 & 32 & 20 & 29 & 21 \\
\hline Percentage of stations with TEC $*$ Sigma $\geqslant+2$ & 14.6 & 16.0 & 44.0 & 34.0 & 25.5 & 78.4 & 98.1 & 60.4 & 37.7 & 54.7 & 39.6 \\
\hline Number of stations with $\mathrm{TEC} *$ Sigma $\leqslant-2$ & 19 & 45 & 24 & 47 & 24 & 12 & 6 & 6 & 3 & 2 & 8 \\
\hline Percentage of stations with TEC $*$ Sigma $\leqslant-2$ & 39.6 & 90.0 & 48.0 & 94.0 & 47.1 & 23.5 & 11.3 & 11.3 & 5.7 & 3.8 & 15.1 \\
\hline
\end{tabular}

Table 4

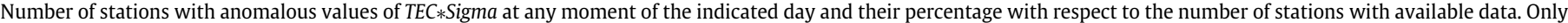
the 10 stations closest to the epicentre are considered.

\begin{tabular}{|c|c|c|c|c|c|c|c|c|c|c|c|}
\hline Day & -10 & -9 & -8 & -7 & -6 & -5 & -4 & -3 & -2 & -1 & 0 \\
\hline Number of stations with TEC $*$ Sigma & 9 & 10 & 10 & 10 & 10 & 10 & 10 & 10 & 10 & 10 & 10 \\
\hline Number of stations with TEC $*$ Sigma $\geqslant+2$ & 1 & 0 & 1 & 0 & 0 & 7 & 10 & 0 & 7 & 10 & 10 \\
\hline Percentage of stations with TEC $*$ Sigma $\geqslant+2$ & 11.1 & 0 & 10.0 & 0 & 0 & 70.0 & 100 & 0 & 70.0 & 100 & 100 \\
\hline Number of stations with TEC $*$ Sigma $\leqslant-2$ & 3 & 10 & 2 & 8 & 10 & 1 & 1 & 1 & 0 & 0 & 1 \\
\hline Percentage of stations with TEC $*$ Sigma $\leqslant-2$ & 33.3 & 100 & 20.0 & 80.0 & 100 & 10.0 & 10.0 & 10.0 & 0 & 0 & 10.0 \\
\hline
\end{tabular}
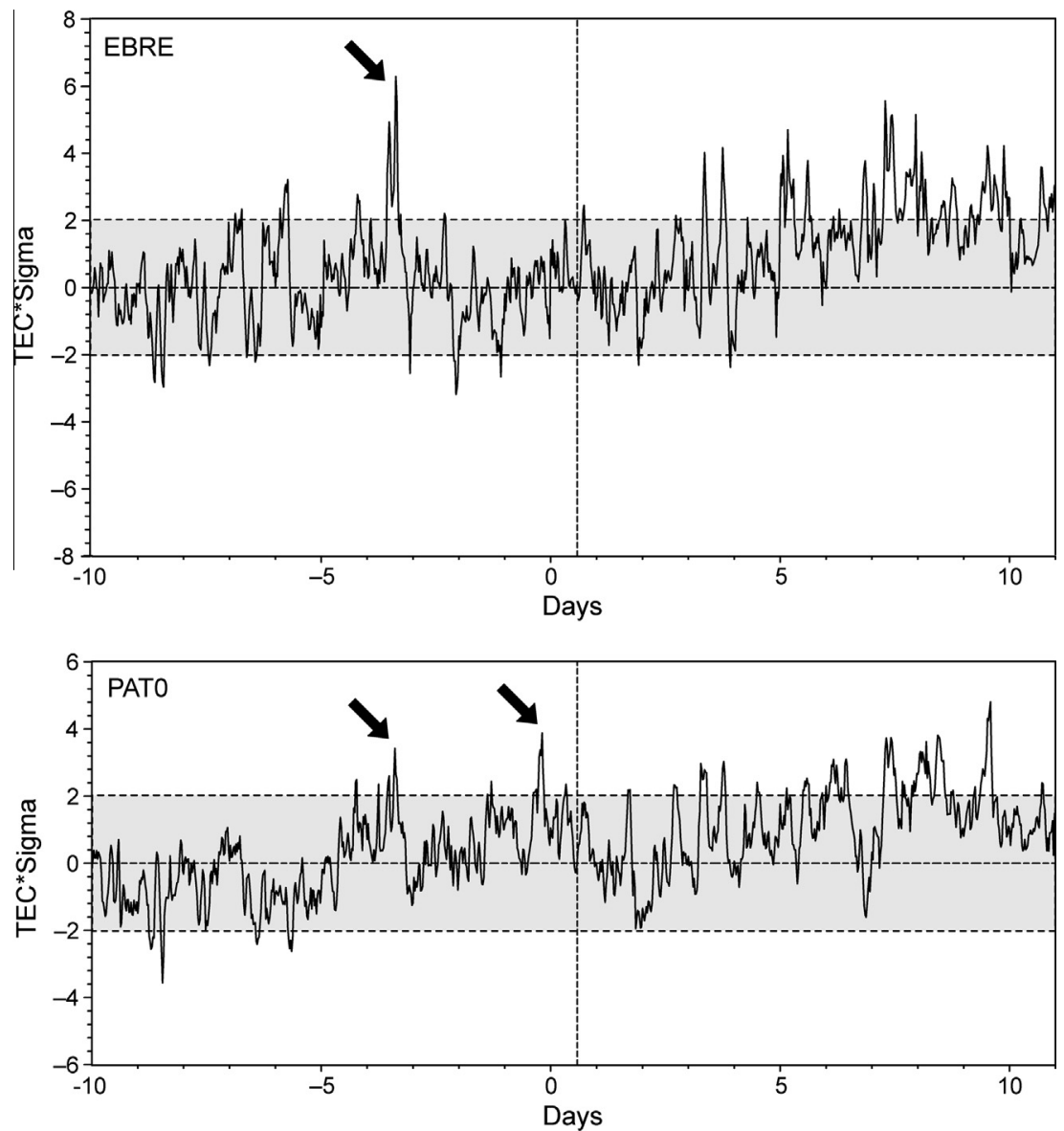

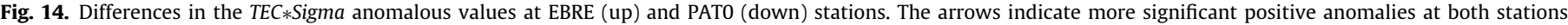

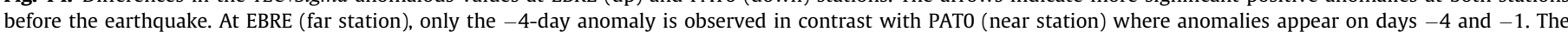
vertical discontinuous line marks the time of the earthquake. The limits for $T E C * S i g m a= \pm 2$ separate the normal values (inside the grey band) from the anomalous ones.

intermediate phase of the process as expected. On the contrary, the second one, the highest anomaly, occurred at 20:00 UT in the final step.

Fig. 16 shows the maps for the most significant hours of the day when the earthquake occurred (day 0). On this day, the sunrise occurred at 05:48 UT in the epicentral area. At 07:00 UT, a clear anomaly $(T E C *$ Sigma $=2.66)$ can be observed over LAMP, the same station where the maximum had been observed during the final phase of the preceding day. This location of the highest anomaly remains until 08:00 UT when $T E C *$ Sigma $=3.11$. It is important to keep in mind that, due to the lack of stations on the northern coast of Africa, the southern border of the anomaly on days -1 and 0 must be critically considered. This circumstance does not diminish the validity of the results presented so far, which reflect the 

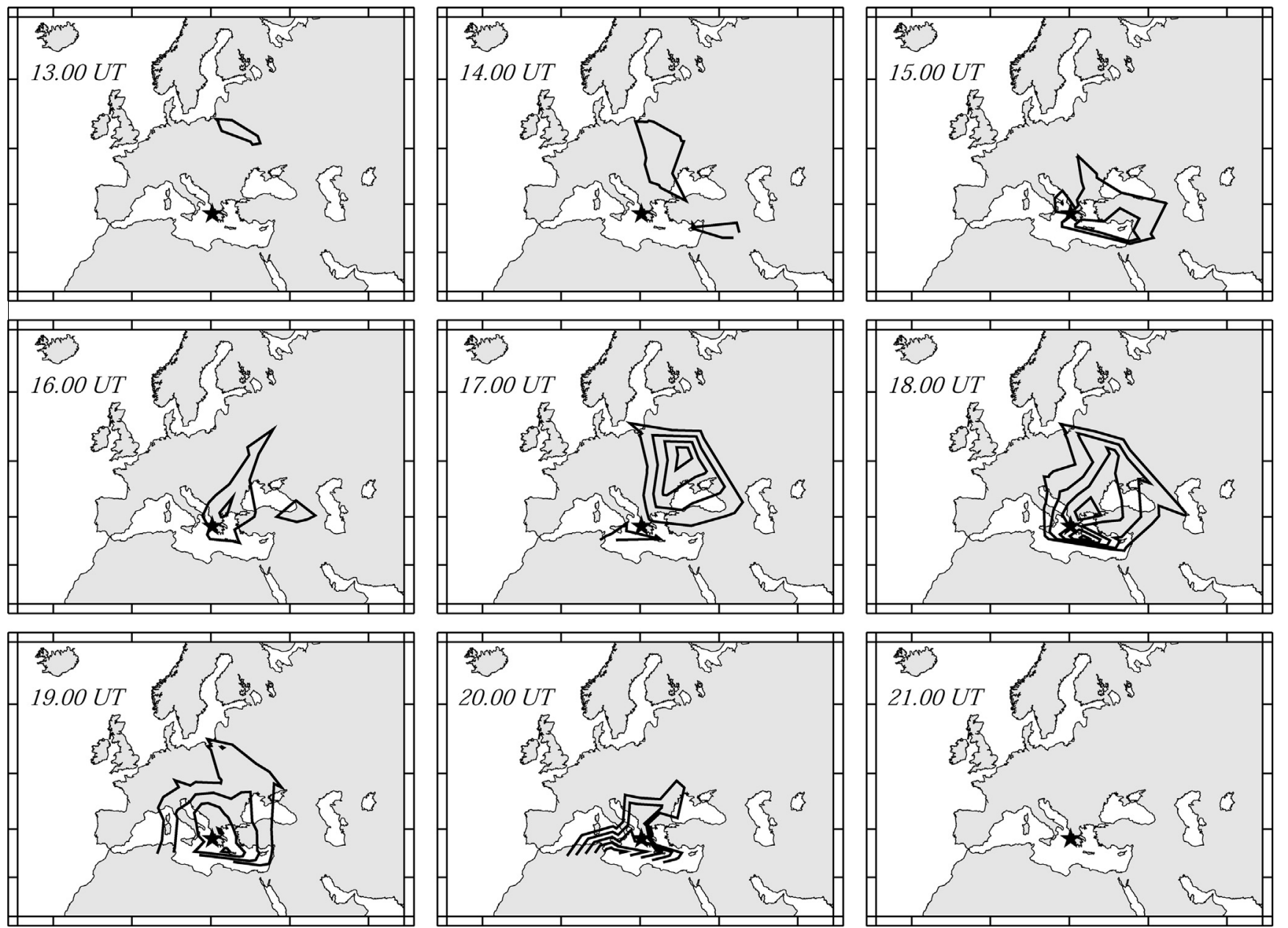

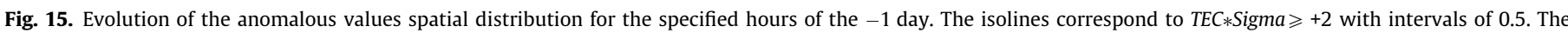
earthquake epicentre is marked by a star.

presence of an anomaly clearly related both temporarily and spatially to the considered earthquake.

Finally, there exist important differences between the spatial and temporal distributions of the anomalous values this day and those corresponding to day -4 when, as commented previously (see Table 3), TEC*Sigma reached anomalous values at 52 of the 53 stations. The first observation is the opposite of what occurred on days -1 and 0 . Anomalous values were also observed during the middle hours of day -4 and not only during the evening hours. This result can be clearly observed in the top row of Fig. 17, which shows the maps for these middle hours (10:00 UT is 12:00 LT in the epicentral region). Moreover, the evolution of the spatial distribution of the anomalous values does not allow for the drawing of any conclusion related to the epicentre location. A similar comment can be applied when considering the evolution of the spatial distribution of the anomalous values between 17:00 UT and 19:00 UT on day -4 , as shown in the lower part of Fig. 17. No conclusions related to the epicentre location can be drawn in this case. In contrast, the anomaly on day -1 reaches its maximum extent during these same hours.

In conclusion, we can say that the results obtained allow for the identification of a clear anomaly from 15:00 to 20:00 UT on day -1 that appears again the day of the earthquake between 07:00 UT and 08:00 UT. The anomalous values reach $T E C *$ Sigma $=4.36$ and
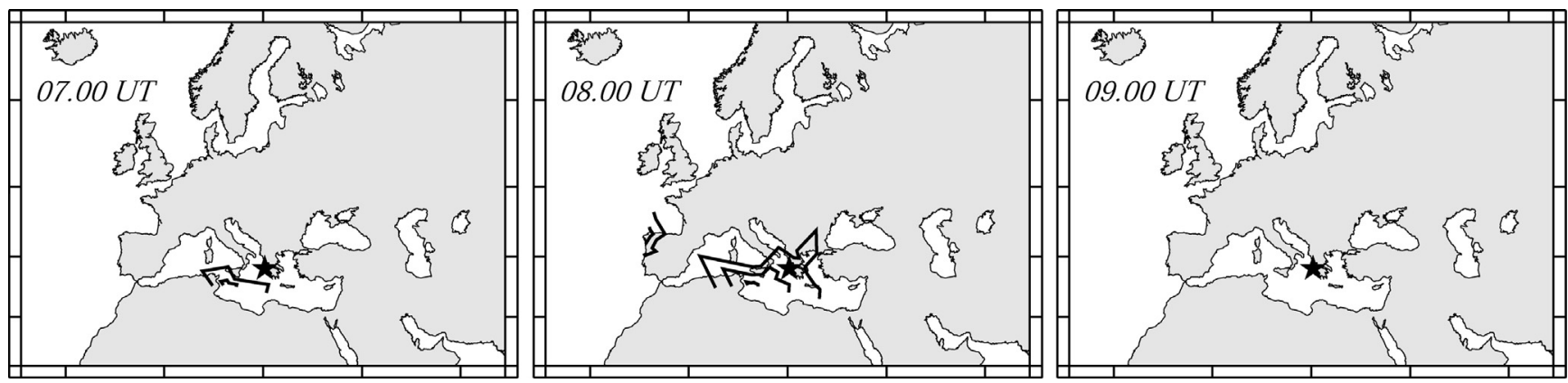

Fig. 16. Evolution of the anomalous values spatial distribution for the specified hours of the earthquake day. The earthquake epicentre is marked by a star. 

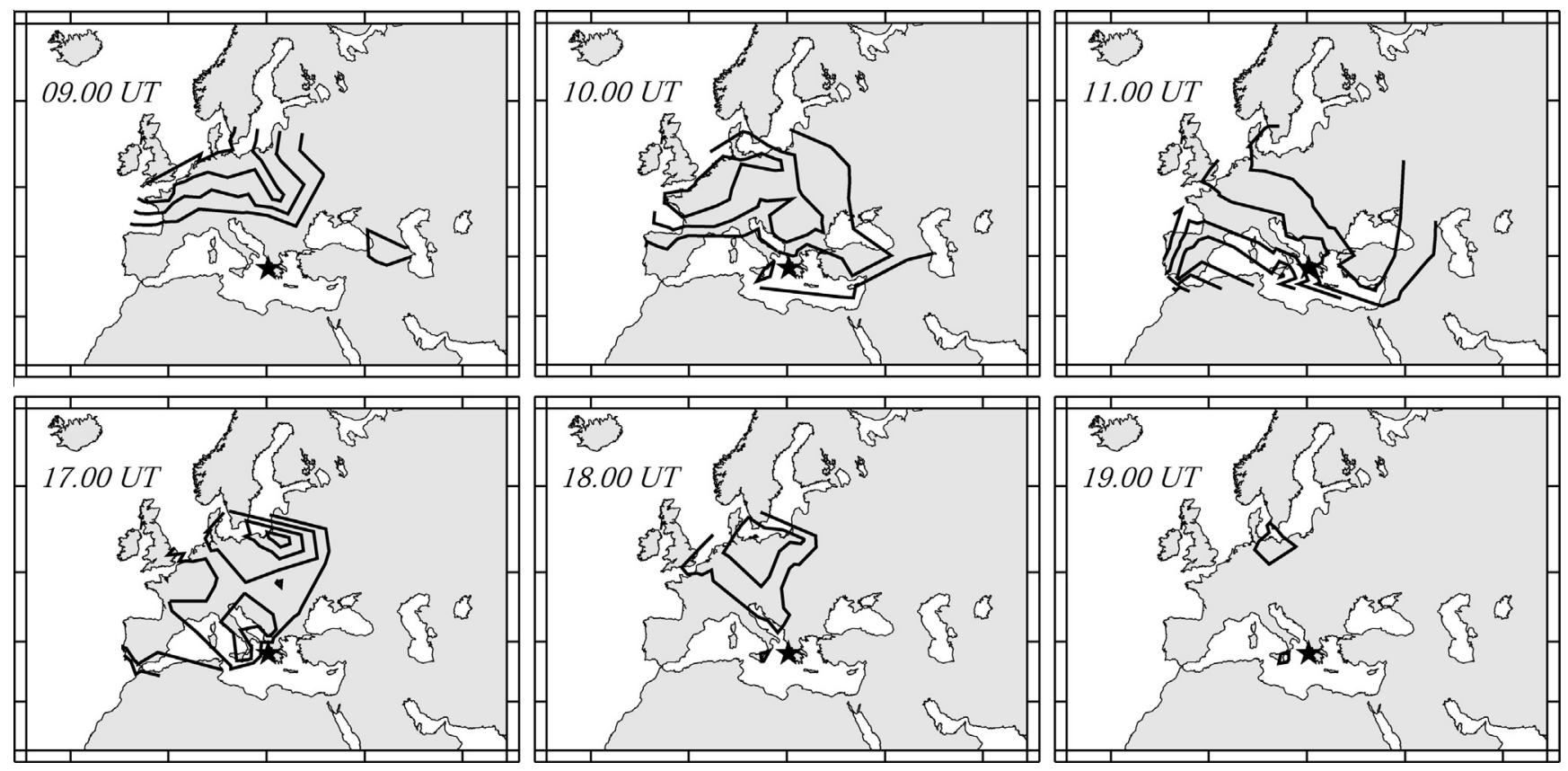

Fig. 17. Evolution of the anomalous values spatial distribution for the specified hours of the -4 day. The earthquake epicentre is marked by a star.

3.11, respectively. Their spatial and temporal distributions support a possible link with the earthquake preparation.

\section{Discussion and conclusions}

The study of VLF signals and ionospheric TEC values that were recorded over the period spanning from 25 days before to 10 after the Argostólion earthquake on January 26, 2014 has shown variations that can be considered related to the earthquake preparation process. The period analysed can be considered quiet from the geomagnetic and solar activity points of view but has important meteorological activity. This activity causes us to be especially cautious in our interpretation of the VLF observations.

VLF radio signals reveal the existence of an approximately 4-day anomaly in the wavelet analysis of the signals received inside the earthquake preparation zone (GRE station) and a significant increase in the variance of the signals received near the preparation zone (CRE station). In addition, clear spikes were recorded at these stations the day before the earthquake. The anomalies reached higher values for the receivers located closer to the epicentre. No anomalies were observed for signals far from the earthquake epicentre (POR receiver). These spatial and temporal distributions indicate a connection to the seismic process. It is important that the signals from the HWU and ICV transmitters (with similar transmission frequencies, $\sim 20 \mathrm{kHz}$ ) show some interference, which is probably caused by the meteorological conditions (thunderstorms), but not enough to disguise the clear effect possibly related to the earthquake occurrence. Moreover, no possible weather related interference is seen in the signals from the other two transmitters, NRK and GB. This fact strengthens the validity of the results obtained from the VLF analysis. It also justifies the use of different radio transmissions in this study and notes its importance in future VLF studies related to earthquakes.

TEC analysis showed two anomalies in the days prior to the earthquake: one four days before and another the preceding day. The first one was registered by the majority of the stations and, after analysing its temporal variation, seems to be unrelated to the earthquake. However, the second anomaly is clearly related to it. This anomaly appears only at stations close to the epicentre; however, the largest change does not occur in the closest stations. The temporal behaviour of this anomaly is characterized by two maxima: the first between 17:00 UT and 20:00 UT on the day before the earthquake and the second on the same day as the earthquake between 7:00 UT and 8:00 UT. The consideration of more demanding limit values as TEC *Sigma $\geqslant+3$ that, for a normal distribution should include $99.6 \%$ of the sample values, would give a very significant anomaly between 17:00 UT and 20:00 UT on day -1 . The extent of this anomaly would be smaller because it is limited by isolines of $T E C * \operatorname{Sigma}=3$. This temporal proximity to the earthquake indicates a possible connection with the earthquake preparation process. In particular, the detection of clear anomalies the day before the earthquake both in VLF and TEC records reinforces the relationship with the physical mechanisms linked to the seismic event. TEC anomalies were also observed (Fig. 12) in the days following the earthquake that apparently could be related to the strong seismic activity that lasted more than 9 days. The geomagnetic conditions remained quiet for at least 10 days after the main shock (Fig. 4), but the simultaneous occurrence of anomalous TEC values at EBRE (far station) and PATO (close station) weakens the claim of a seismic origin. The analysis of geomagnetic, solar and meteorological conditions during the study supports a link between the observed TEC anomalies and the earthquake process. A more detailed analysis of the VLF and TEC behaviours during the entire seismic series is advisable.

These results, obtained via the joint consideration of two techniques that focus on clearly different physical phenomena, allow us to confirm the existence of processes that can be considered related to earthquakes.

Much work must be done to clarify the perturbations in the earthquake preparation area using experiments that study many different physical parameters on both the surface and in the neutral and conducting atmosphere.

\section{Acknowledgements}

The Portuguese team acknowledges the support of the Portuguese Science and Technology Foundation (FCT) through the project Pest/OE/CTE/UI0078/2014 and the FCT/FEDER-COMPETE 
project EAC (PTDC/GEO-FIQ/4178/2012) FCOMP-01-0124-FEDER029197. We are grateful to Samuel Bárias for the maintenance of the Portuguese radio antennas, to Elisa Cardoso for her help with wavelet theory, to Tommaso Maggipinto for instructing us on the MatLab ${ }^{\circledR}$ wavelet script and to Rui Salgado for the interpretation of the weather data. H.G.S is grateful to FCT for the postdoctoral fellowship SFRH/BPD/63880/2009 and to Calouste Gulbenkian Foundation (Portugal) for the award Estímulo à Criatividade e à Qualidade na Actividade de Investigação (2010). The Spanish team acknowledges the support of the Spanish Ministry of Economy and Competitiveness through the project CGL2014-62113-EXP. This work is part of the research activity of the Spanish Team "Grupo de Estudios Ionosféricos y Técnicas de Posicionamiento Satelital (GNSS)" financed by the Universidad Complutense de Madrid. The authors are very grateful to Luigi Ciraolo for his collaboration. They also want to thank the International GNSS Service, IGS, and EUREF Permanent Network (EPN) for providing the GNSS data; the World Data Center for Geomagnetism Kyoto for the Dst and Kp index values; and Intermagnet for the magnetic field data. AVVSO, the Russian Weather website and OMNIWeb Data Explorer from NASA, also provided very valuable data. Figures were drawn using the Generic Mapping Tools (Wessel and Smith, 1998). The final version of the article was prepared when M.H. was on sabbatical leave at the Abdus Salam International Centre for Theoretical Physics (Trieste, Italy) granted by the Spanish Ministry of Education, Culture and Sports. The authors are grateful to Dr. Kazimirowsky and two anonymous reviewers for their comments and suggestions, which improved the quality of the present manuscript.

\section{References}

Afraimovic, E.L., Voeikov, S.V., Ishin, A.B., Perevalova, N.P., Ruzhin, Y..Ya., 2008. Variations in the Total Electron Content during the powerful Typhoon of August 5-112006, near the Southeastern Coast of China. Geomag Aeron. 48 (5), 674-679.

Artru, J., Ducic, J.V., Kanamori, H., Lognonné, Ph., Murakami, M., 2005. Ionospheric detection of gravity waves induced by tsunamis. Geophys. J. Int. 160, 840-848. http://dx.doi.org/10.1111/j.1365-246X.2005.02552.x.

Bauer, S.J., 1958. An apparent ionosphere response to the passage of hurricanes. J. Geophys. Res. 63, 265-269.

Biagi, P.F. Castellana, L., Maggipinto, T., Piccolo, R., Minafra, A., Ermini, A., Martellucci, S., Bellecci, C., Perna, G., Capozzi, V., Molchanov, O.A., Hayakawa, M., 2006. LF radio anomalies revealed in Italy by the wavelet analysis: Possible preseismic effects during 1997-1998. Phys. Chem. Earth 31, 403-408. http://dx. doi.org/10.1016/j.pce.2005.10.001.

Biagi, P.F., Maggipinto, T., Righetti, F., Loiacono, D., Schiavulli, L., Ligonzo, T., Ermini, A., Moldovan, I.A., Moldovan, A.S., Buyuksarac, A., Silva, H.G., Bezzeghoud, M., Contadakis, M.E., 2011. The European VLF/LF radio network to search for earthquake precursors: setting up and natural/man-made disturbances. Nat. Hazards Earth Syst. Sci. 11, 333-341. http://dx.doi.org/10.5194/nhess-11-3332011.

Biagi, P.F., Castellana, L., Maggipinto, T., Loiacono, D., Augelli, V., Schiavulli, L., Ermini, A., Capozzi, V., Solovieva, M.S., Rozhnoi, A.A., Molchanov, O.A., Hayakawa, M., 2008. Disturbances in a VLF radio signal prior the $M=4.7$ offshore Anzio (central Italy) earthquake on 22 August 2005. Nat. Hazards Earth Syst. Sci. 8, 1041-1048.

Bishop, R.L., Aponte, N., Earle, G.D., Sulzer, M., Larsen, M.F., Peng, G.S., 2006. J. Geophys. Res. http://dx.doi.org/10.1029/2006JA011668.

Chen, T.F., Shen, J., 2005. Image Processing and Analysis Variational, PDE, Wavelet and Stochastic Methods. Society of Applied Mathematics, ISBN 0-89871-598-X.

Ciraolo, L., Azpilicueta, F., Brunini, C., Meza, A., Radicella, S.M., 2007. Calibration errors on experimental slant total electron content (TEC) determined with GPS. J. Geodesy 81 (2), 111-120.

Davidenko, D., Pulinets, S.A., 2012. Analysis of the ionosphere behavior before strong Greek earthquakes with $M>6.0$ over a period of 2006-2011. In: Proceedings Pre-Earthquakes Seventh Frame Work Programma Final Meeting, Yuzhno-Sakhalinsk, Russia.

Davies, K., Baker, D.M., 1965. Ionospheric effects observed around the time of the Alaskan earthquake of March 28, 1964. J. Geophys. Res. 70, 2251-2253. http:// dx.doi.org/10.1029/JZ070i009.

Dobrovolsky, I.R., Zubkov, S.I., Myachkin, V.I., 1979. Estimation of the size of earthquake preparation zones. Pure Appl. Geophys. 117, 1025-1044.

Freund, F., 2013. Earthquake Forewarning - a multidisciplinary challenge from the ground up to space. Acta Geophys. 61, 775-807. http://dx.doi.org/10.2478/ s11600-013-0130-4.
Gokhberg, M.B., Gufeld, I.L., Rozhnoi, A.A., Marenko, V.F., Yampolsky, V.S. Ponomarev, E.A., 1989. Study of seismic influence on the ionosphere by super long wave probing of the Earth-ionosphere waveguide. Phys. Earth. Planet. Inter. 57, 64-67.

González, W.D., Joselyn, J.A., Kamide, Y., Kroehl, H.W., Rostoker, G., Tsurutani, B.T., Vasyliunas, V.M., 1994. What is a geomagnetic storm? J. Geophys. Res. 99, 5771-5792. http://dx.doi.org/10.1029/93JA02867.

Harrison, R.G., Aplin, K.L., Rycroft, M.J., 2014. Earthquake-cloud coupling through the global atmospheric electric circuit. Nat. Hazards Earth Syst. Sci. 14, 773777.

Kakinami, Y., Kamogawa, M., Onishi, T., Mochizuki, K., Lebreton, J.P., Watanabe, S. Yamamoto, M.Y., Mogi, T., 2013. Validation of electron density and temperature observed by DEMETER. Adv. Space Res. 52, 1267-1273. http://dx.doi.org/ 10.1016/j.asr.2013.07.003.

Kazimirovsky, E., 2002. Coupling from below as a source of ionospheric variability: a review. Ann. Geophys. http://dx.doi.org/10.4401/ag-3482.

Kazimirovsky, E., Herraiz, M., De la Morena, B.A., 2003. Effects on the ionosphere due to phenomena occurring below it. Survey Geophys. 24, 139-184.

Lastovicka, J., 2006. Forcing of the ionosphere by waves from below. J. Atmos. SolarTerrrestrial Phys. 68, 479-497.

Liu, J.Y., Sun, Y.Y., Tsai, H.F., Lin, C.H., 2012. Seismo-traveling ionospheric disturbances triggered by the 12 May 2008 M 8.0 Wenchuan Earthquake. Terr. Atmos. Ocean. Sci. 23, 9-15. http://dx.doi.org/10.3319/TA0.2011.08.03.01 (T).

Lopes, I., Silva, H.G., 2015. Looking for granulation and periodicities imprints in the sunspot time series. Astrophys. J. 804, 120-130. http://dx.doi.org/10.1088 0004-637X/804/2/120.

Mannucci, A.J., Wilson, B.D., Yuan, D.N., Ho, C.H., Lindqwister, U.J., Runge, T.F., 1998. A global mapping technique for GPS-derived ionospheric total electron content measurments. Radio Sci. 33, 565-582.

Mezentsev, A., Füllekrug, M., 2013. Mapping the radio sky with an interferometric network of low-frequency radio receivers. J. Geophys. Res. 118, 8390-8398 http://dx.doi.org/10.1002/jgrd.50671.

Meyers, S.D., Kelley, B.G., ÓBrian, J.J., 1993. An introduction to wavelet analysis in oceanography and meteorology: with application to the dispersion of Yanai waves. Mon. Weather Rev. 121, 2858-2866.

Molchanov, O., Fedorov, E., Schekotov, A., Gordeev, E., Chebrov, V., Surkov, V. Rozhnoi, A., Andreevsky, S., Iudin, D., Yunga, S., Lutikov, A., Hayakawa, M., Biagi, P.F., 2004. Lithosphere-atmosphere-ionosphere coupling as governing mechanism for preseismic short-term events in atmosphere and ionosphere. Nat. Haz. Earth Syst. Sci. 4, 757-767.

Moore, G., 1964. Magnetic Disturbances preceding the 1964 Alaska earthquake. Nature 203, 508-509. http://dx.doi.org/10.1038/203508b0.

Nemec, F., Santolík, O., Parrot, M., Berthelier, J.J., 2008. Spacecraft observations of electromagnetic perturbations connected with seismic activity. Geophys. Res. Lett. 35, L05109. http://dx.doi.org/10.1029/2007GL032517.

Ouzounov, D., Pulinets, S., Romanov, A., Romanov, A., Tsybulya, K., Davidenko, D., Kafatos, M., Taylor, P., 2011. Atmosphere-ionosphere response to the M9 Tohoku earthquake revealed by multi-instrument space-borne and ground observations: preliminary results. Earthq. Sci. 24, 557-564. http://dx.doi.org/ 10.1007/s11589-011-0817-z.

Perevalova, N.P., Ishin, A.B., 2011. Effects of tropical cyclones in the ionosphere from data of sounding by GPS signals. Izv. Atmos. Oceanic Phys. 47 (9), 1072-1083. http://dx.doi.org/10.1134/S000143381109012X.

Polyakova, A.S., Perevalova, N.P., 2013. Comparative analysis of TEC distrubances over tropical cyclone zones in the North-West Pacific Ocean. Adv. Space Res. 52, 1416-1426. http://dx.doi.org/10.1016/j.asr.2013.07.029.

Pulinets, S.A., Boyarchuk, K.A., 2004. Ionospheric Precursors of Earthquakes. Springer, Berlin, ISBN 978-3-540-20839-6.

Pulinets, S.A., Ouzounov, D., 2011. Lithosphere-Atmosphere-Ionosphere Coupling (LAIC) model - An unified concept for earthquake precursors validation. J. Asian Earth Sci. 41, 371-382. http://dx.doi.org/10.1016/j. jseaes.2010.03.005.

Righetti, F., Biagi, P.F., Maggipinto, T., Schiavulli, L., Ligonzo, T., Ermini, A., Moldovan, I.A., Moldovan, A.S., Buyuksarac, A., Silva, H.G., Bezzeghoud, M., Contadakis, M. E., Arabelos, D.N., Xenos, T.D., 2012. Wavelet analysis of the LF radio signals collected by the European VLF/LF network from July 2009 to April 2011. Ann. Geophys. 55 (1), 171-180. http://dx.doi.org/10.4401/ag-5188.

Rishbeth, R., 2006. F-region links with the lower atmosphere? J. Atmos. SolarTerristrial Phys, 68, 469-478. http://dx.doi.org/10.1016/j.jastp.2005.03.017.

Rozhnoi, A., Solovieva, M., Levin, B., Hayakawa, M., Fedun, V., 2014. Meteorological effects in the lower ionosphere as based on VLF/LF signal observations. Nat. Hazards Earth Syst. Sci. 14, 2671-2679. http://dx.doi.org/10.5194/nhess-142671-2014.

Rozhnoi, A., Solovieva, M., Molchanov, O., Schwingenschuh, K., Boudjada, M., Biagi, P.F., Maggipinto, T., Castellana, L., Ermini, A., Hayakawa, M., 2009. Anomalies in VLF radio signals prior the Abruzzo earthquake $(M=6.3)$ on 6 April 2009. Nat. Hazards Earth Syst. Sci. 9, 1727-1732. http://dx.doi.org/10.5194/nhess-9-1727 2009.

Saha, A., Guha, A., Kumar De, B., Roy, R., Choudhury, A., Banik, T., Dhar, P. Chakraborty, M., 2014. Precursory signature of several major earthquakes studied using $40 \mathrm{kHz}$ low frequency signal. Adv. Space Res. 54, 617-627.

Silva, H.G., Conceição, R., Melgão, M., Nicoll, K., Mendes, P.B., Tlemçani, M., Reis, A H., Harrison, R.G., 2014. Atmospheric electric field measurements in urban environment and the pollutant aerosol weekly dependence. Environ. Res. Lett 9, 114025. http://dx.doi.org/10.1088/1748-9326/9/11/114025. 
Silva, H.G., Bezzeghoud, M., Oliveira, M.M., Reis, A.H., Rosa, R.N., 2013. A simple statistical procedure for the analysis of radon anomalies associated with seismic activity. Ann. Geophys. 56, R0106. http://dx.doi.org/10.4401/ ag-5570.

Silva, H.G. Bezzeghoud, M., Reis, A.H., Rosa, R.N., Tlemçani, M. Araújo, A.A., Serrano, C., Borges, J.F., Caldeira, B., Biagi, P.F., 2011. Atmospheric electrical field decrease during the M4.1 Sousel earthquake (Portugal). Nat. Haz. Earth Syst. Sci. 11, 987-991. http://dx.doi.org/10.5194/nhess-11-987-2011.
Torrence, C., Compo, G.P., 1998. A practical guide to wavelet analysis. Bull. Amer. Meteor. Soc. 79, 61-78, http://paos.colorado.edu/research/wavelets/ (retrieved at 10.07.14).

Wessel, P., Smith, W.H.F., 1998. New, improved version of the Generic Mapping Tools released. EOS Trans. AGU 79, 579.

Yao, Y.B., Chen, P., Wu, H., Zhang, S., Peng, W.F., 2012. Analysis of ionospheric anomalies before the 2011 Mw 9.0 Japan earthquake. Chin. Sci. Bull. 57, 500-510. http://dx.doi.org/10.1007/s11434-011-4851-y. 